\title{
Solar Backscatter UV (SBUV) total ozone and profile algorithm
}

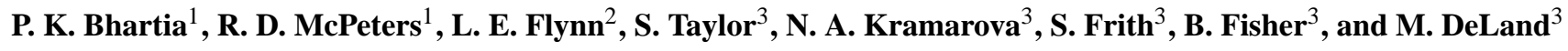 \\ ${ }^{1}$ Laboratory for Atmospheres, NASA Goddard Space Flight Center, Greenbelt, MD, USA \\ ${ }^{2}$ NOAA NESDIS, College Park, Maryland, USA \\ ${ }^{3}$ Science Systems and Applications Inc., Lanham, MD, USA
}

Correspondence to: P. K. Bhartia (pawan.bhartia@nasa.gov)

Received: 16 July 2012 - Published in Atmos. Meas. Tech. Discuss.: 21 August 2012

Revised: 29 July 2013 - Accepted: 15 August 2013 - Published: 7 October 2013

\begin{abstract}
We describe the algorithm that has been applied to develop a $42 \mathrm{yr}$ record of total ozone and ozone profiles from eight Solar Backscatter UV (SBUV) instruments launched on NASA and NOAA satellites since April 1970. The Version 8 (V8) algorithm was released more than a decade ago and has been in use since then at NOAA to produce their operational ozone products. The current algorithm (V8.6) is basically the same as V8, except for updates to instrument calibration, incorporation of new ozone absorption cross-sections, and new ozone and cloud height climatologies. Since the V8 algorithm has been optimized for deriving monthly zonal mean (MZM) anomalies for ozone assessment and model comparisons, our emphasis in this paper is primarily on characterizing the sources of errors that are relevant for such studies. When data are analyzed this way the effect of some errors, such as vertical smoothing of short-term variability, and noise due to clouds and aerosols diminish in importance, while the importance of others, such as errors due to vertical smoothing of the quasi-biennial oscillation (QBO) and other periodic and aperiodic variations, become more important. With V8.6 zonal mean data we now provide smoothing kernels that can be used to compare anomalies in SBUV profile and partial ozone columns with models. In this paper we show how to use these kernels to compare SBUV data with Microwave Limb Sounder (MLS) ozone profiles. These kernels are particularly useful for comparisons in the lower stratosphere where SBUV profiles have poor vertical resolution but partial column ozone values have high accuracy. We also provide our best estimate of the smoothing errors associated with SBUV MZM profiles. Since smoothing errors are the largest source of uncertainty in these profiles, they can be treated as error bars in deriving interannual variability and trends using SBUV data and for comparing with other
\end{abstract}

measurements. In the V8 and V8.6 algorithms we derive total column ozone by integrating the SBUV profiles, rather than from a separate set of wavelengths, as was done in previous algorithm versions. This allows us to extend the total ozone retrieval to $88^{\circ}$ solar zenith angle (SZA). Since the quality of total column data is affected by reduced sensitivity to ozone in the lower atmosphere by cloud and Rayleigh attenuation, which gets worse with increasing SZA, we provide our best estimate of these errors, as well as the kernels that can be used to test the sensitivity of the derived columns to longterm changes in ozone in the lower atmosphere.

\section{Introduction}

Systematic measurement of total ozone and ozone profiles from space started with the launch of the Backscatter UV (BUV) instrument on NASA's Nimbus-4 satellite in April 1970. Since then 9 additional instruments of progressively improved design have been launched on various NASA and NOAA satellites (Frederick et al., 1986; Heath et al., 1975; Mateer et al., 1971). The Solar Backscatter UV (SBUV) instrument on the Nimbus-7 satellite launched in October 1978 was mated with the Total Ozone Mapping Spectrometer (TOMS) instrument, which was designed to produce global maps of total ozone (Heath et al., 1975). The data produced from the SBUV series of instruments now span more than $42 \mathrm{yr}$ with overlap among most instruments, except a 6 yr gap between the Nimbus- 4 and Nimbus- 7 satellites. The record from the TOMS series of instruments is shorter and has more gaps. In this paper we focus only the SBUV data record. 
Over the years several different algorithms have been applied to process SBUV data, but only a few have been published in the open literature (Bhartia et al., 1996 and the references therein). The current version of the algorithm (V8.6) is a modified version of the V8 algorithm that was developed in the late 1990s. Data produced from V8 and the details of the algorithm were first released at the 2004 Quadrennial Ozone Symposium in Greece. This algorithm has been in use at NOAA ever since (Flynn, 2007) to produce operational ozone products. Differences between V8 and V8.6 are small. These differences and the differences between V6 and V8 are described in this paper. (The V7 algorithm, a modification of the V6 algorithm planned in the late 1980s, was never completed. Version 7 SBUV data referred to in the literature, e.g., Stolarski and Frith, 2006, are for total ozone only which was produced using the TOMS Version 7 algorithm.) Most of the recent work in this field has been focused on deriving improved ozone profiles in the lower stratosphere and troposphere by taking advantage of the extra information, redundancy, and low noise characteristics of hyperspectral instruments, like GOME, SCIAMACHY and OMI (Hasekamp and Landgraf, 2001; Hoogen et al., 1999; Liu et al., 2005, 2010; Meijer et al., 2006; Munro et al., 1998; van der A et al., 2002)

This paper discusses the scientific algorithm used to process the data, introduces various types of smoothing kernels that need to be considered in interpreting the data, discusses how these kernels can be used in estimating errors, and applies these concepts in comparing SBUV with Aura Microwave Limb Sounder (MLS) data. It is one of the 5 papers describing various aspects of this new dataset, including an overview paper (McPeters et al., 2013), two validation papers (Kramarova et al., 2013b; Labow et al., 2013) and one dealing with the effect of smoothing on the analysis of the quasi-biennial oscillation (QBO) (Kramarova et al., 2013a). These papers apply the concepts discussed in this paper.

In Sect. 2 we discuss the key features of the SBUV instrument relevant for developing the algorithm and understanding data quality. In Sect. 3 we provide details of the V8.6 algorithm. Section 4 discusses sources of error. In Sect. 5 we show comparisons between NOAA-17 SBUV/2 and Aura MLS instruments.

\section{SBUV instrument series}

The SBUV instrument series consists of 10 instruments launched on 3 NASA and 7 NOAA satellites since 1970. Data from eight of these 10 instruments, shown in Fig. 1, are included in the current V8.6 dataset. Data from the AE-E BUV instrument (launched in November 1975) are no longer available from the NASA archives, although a study comparing AE-E BUV radiance data with models has been published (Prather, 1981). Data from the NOAA-19 SBUV/2 instrument (launched in February 2009) are being processed and will be added to the V8.6 dataset after they are validated.

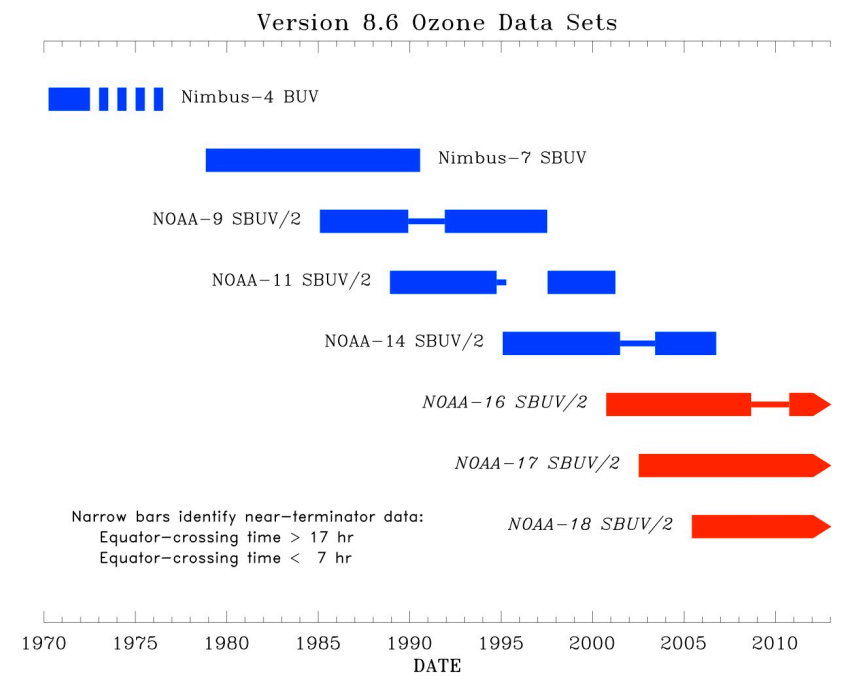

Fig. 1. Timeline of the datasets re-processed using Version 8.6 algorithm. The coverage of Nimbus-4 BUV was sparse in later years. Several NOAA instruments have missing data when the spacecraft was in a near-terminator orbit. Instruments currently operating are shown in red.

In addition, the engineering model of the SBUV/2 instrument was flown as the shuttle BUV (SSBUV) instrument on eight NASA space shuttle missions during the period 1989-1996. These short-duration missions were designed to validate the calibration of overflying SBUV/2 instruments (Hilsenrath et al., 1993). The SSBUV data have not been reprocessed using the V8.6 algorithm.

From an algorithm development perspective the design of these instruments has changed very little over the past 4 decades. All instruments view the Earth in the nadir along the satellite track, with approximately $11.3^{\circ} \times 11.3^{\circ}$ field of view, corresponding to approximately $170 \mathrm{~km} \times 170 \mathrm{~km}$ at the surface for SBUV/2 $(200 \mathrm{~km} \times 200 \mathrm{~km}$ for SBUV $)$. They measure some 6 orders of magnitude change in the backscattered radiance between 250 and $340 \mathrm{~nm}$ by employing a double grating monochromator to minimize spectral straylight from longer wavelengths and a photomultiplier tube (PMT) detector with multiple electronic gain ranges to provide high signal-to-noise ratio. In their primary operating mode, all instruments measure 12 discrete wavelength bands sequentially, with a triangular response function of $1.1 \mathrm{~nm}$ full width at half maximum. The measurement sequence takes $24 \mathrm{~s}$ to step through all 12 wavelengths (18 s for Nimbus-7 SBUV), which extends the scanning region in the along-track direction to create an effective footprint of $170 \mathrm{~km} \times 340 \mathrm{~km}(200 \mathrm{~km} \times 330 \mathrm{~km}$ for Nimbus-7). Beginning with Nimbus-7 SBUV, all instruments were modified to include a chopper wheel to reduce charged particle contamination and a continuous scan mode in which the instrument sweeps through the wavelength range $160-400 \mathrm{~nm}$ with 0.15-0.20 sampling (Heath et al., 1975). Continuous scan 
Table 1. Spectroscopic parameters for the NOAA-17 SBUV/2 sensor calculated assuming $1.1 \mathrm{~nm}$ triangular slit function, $1 \mathrm{~atm}=2.148 \times 10^{29} \mathrm{mols} \mathrm{m}^{-2}$ and $1 \mathrm{~atm}-\mathrm{cm}=2.687 \times 10^{19} \mathrm{mols} \mathrm{cm}^{-2}$. Note that the SBUV forward model accounts for variations in Rayleigh scattering coefficient with height due to change in gravity and band-averages the radiances calculated using ozone and temperature profiles for improved accuracy.

\begin{tabular}{lrrrr}
\hline $\begin{array}{l}\text { Wavelength } \\
(\mathrm{nm})\end{array}$ & $\begin{array}{r}\text { Rayleigh } \\
\text { scatt coeff } \\
\left(\mathrm{atm}^{-1}\right)\end{array}$ & $\begin{array}{r}\text { Ozone sensitivity- } \\
\text { weighted temperature, } \\
T_{\text {eff }}(\mathrm{K})\end{array}$ & $\begin{array}{r}\text { Ozone abs } \\
\text { coefficient at } T_{\text {eff }} \\
\left(\alpha_{\text {eff }}\right)\left(\mathrm{atm}_{-} \mathrm{cm}^{-1}\right)\end{array}$ & $\begin{array}{r}\text { Temp } \\
\text { sensitivity of } \\
\alpha_{\text {eff }}(\% / \mathrm{K})\end{array}$ \\
\hline 251.9 & 2.618 & 272.8 & 303 & 0 \\
273.5 & 1.819 & 268.2 & 171 & 0.02 \\
283.0 & 1.565 & 261.3 & 80.1 & 0.04 \\
287.6 & 1.459 & 256.4 & 49.3 & 0.06 \\
292.2 & 1.363 & 249.6 & 28.1 & 0.09 \\
297.5 & 1.259 & 239.8 & 13.8 & 0.13 \\
301.9 & 1.182 & 229.2 & 7.45 & 0.06 \\
305.8 & 1.119 & 224.5 & 4.27 & 0.09 \\
312.5 & 1.019 & 223.4 & 1.64 & 0.16 \\
317.5 & 0.952 & 223.3 & 0.862 & 0.11 \\
331.2 & 0.794 & 223.3 & 0.142 & 0.21 \\
339.8 & 0.712 & 223.3 & 0.024 & 0.61 \\
\hline
\end{tabular}

solar measurements have been used to monitor wavelength calibration. Changes made to the instruments since then have been modest. They are described in Frederick et al. (1986). Table 1 provides wavelengths and the spectroscopic parameters for the NOAA-17 SBUV/2 instrument. The ozone sensitivity-weighted temperature was calculated using a climatological mean mid-latitude temperature profile weighted by the ozone sensitivity of the wavelength as a function of height at $45^{\circ}$ solar zenith angle. The ozone absorption coefficient is based on data from Malicet et al. (1995).

The primary method of determining long-term instrument calibration of SBUV instruments is through measurement of the extraterrestrial solar irradiance, obtained by using a reflective solar diffuser. Accurate tracking of changes in diffuser reflectivity has been a challenge, even though an onorbit calibration system was added to the SBUV/2 instruments. Deland et al. (2012) discuss these results in more detail. The long-term calibration of these instruments has therefore been supplemented by applying a variety of "soft" calibration techniques to characterize instrument response changes using carefully selected radiance data. For example, ice radiance measurements over Antarctica have been used to determine instrument degradation at $340 \mathrm{~nm}$ (Huang et al., 2003), and to correct any wavelength-independent bias in the radiance calibration. The overall spectral dependence of the response change is usually roughly linear between 250 and $340 \mathrm{~nm}$, with larger degradation rates at shorter wavelengths (DeLand et al., 2012).

\section{SBUV Version 8.6 algorithm}

Since the V8 algorithm was never formally published we describe the V8.6 algorithm using the V6 algorithm (Bhartia et al., 1996) as the basis for comparison. Bhartia et al. (1996) provide many details regarding the information content of the UV radiances and discuss several heritage algorithms, including the "c-sigma" algorithm that solves the radiative transfer equation analytically to produce a 2-parameter ozone profile in the upper stratosphere (McPeters, 1980). The V6 algorithm was based on a two-step approach. The first step consisted of creating a good first guess profile using a simplified retrieval method. An upper stratospheric profile was created using the c-sigma method, and the lower profile was constructed by interpolating within a 21-profile dataset using total ozone derived from a pair algorithm (Klenk et al., 1982). These 21 profiles, popularly known as the TOMS standard profiles, vary with latitude and total ozone and capture a large fraction of the variance of the ozone profiles (Wellemeyer et al., 1997). Smoothly joined upper and lower profiles were used as a priori in step 2. The step 2 algorithm was based on a retrieval method proposed by Twomey (1963). Though Rodger's optimal estimation expression (Rodgers, 1976) was used in the actual software, the V6 algorithm was not strictly an optimal estimation (OE) technique. In OE the a priori error covariance should reflect the error associated with the a priori that is used. The V6 algorithm used a matrix whose terms were selected by trial and error, conceptually similar to the way one selects the $\gamma$ term in the Twomey algorithm to constrain the retrieval. By contrast, the V8 algorithm is a one-step algorithm in which one uses a month/latitude climatology of ozone profiles constructed using various satellite and ozonesonde datasets as a priori (McPeters et al., 2007). Starting with the V8 algorithm we derive total ozone by integrating the retrieved profile. This allows us to extend the retrievals to $88^{\circ}$ solar zenith angle. Although the V8 algorithm also derives total ozone from the older pair algorithm 
(Klenk et al., 1982), and they are provided in some datasets, we do not recommend their use for scientific studies.

Changes from the V8 and the V8.6 algorithms include new ozone (McPeters and Labow, 2012) and cloud pressure (Haffner, 2011) climatologies, a new ozone absorption cross-section dataset, and updates to the calibration of several SBUV instruments. In V8 we used the UV ozone absorption dataset from Bass and Paur (1985). In V8.6 we use Malicet et al. (1995). At the shortest 8 SBUV wavelengths the differences between the two are less than $1 \%$ (see Supplement Fig. S1). Since SBUV mostly uses these wavelengths in the retrieval we do not expect any significant change in the ozone profile, consistent with results shown in Figs. 2 and 3. Our decision to use the more recent dataset was based on the recommendation by Liu et al. (2007), though their study focuses largely on the longer wavelengths. The cloud pressure climatology is based on optical centroid pressure (OCP) derived from rotational Raman scattering using OMI data (Vasilkov et al., 2008). Vasilkov et al. (2004) show that OCP provides a more reliable estimate of total ozone than that obtained using cloud-top pressure. Figure S2 in the Supplement compares the two cloud climatologies. Figures 2 and 3 show the impact of each individual parameter on the retrieved $\mathrm{O}_{3}$ profiles (obtained by replacing each parameter at a time in the V8.6 algorithm by the parameter used in V8). These results show that the changes from V8 and V8.6 are largely due to changes in instrument calibration (DeLand et al., 2012). Figure 4 shows that V8.6 results agree as well or better with UARS and Aura MLS.

The following describes the details of the V8.6 algorithm.

\subsection{Forward model}

The forward model used to compute the top-of-theatmosphere (TOA) radiances at SBUV wavelengths is essentially the same as that used in V6. It is based on the vector radiative transfer code developed by Dave (1964) with modifications to account for molecular anisotropy by Ahmad and Bhartia (1995) and rotational Raman scattering (Ring effect) correction developed by Joiner et al. (1995). The primary difference is that we now use Malicet et al. (1995) ozone absorption cross-sections instead of those from Bass and Paur (1985). To account for the temperature dependence of the cross-section we use a month/latitude climatology of temperatures developed using NOAA temperature datasets. This climatology is also used to convert from a pressure to an altitude scale to account for the atmospheric curvature in computing the radiances. As in V6 the radiance is calculated assuming the atmosphere contains no aerosols. Aerosol scattering effects are indirectly estimated using a Lambertian reflectivity model (Dave, 1977, 1978). In this model the Sunnormalized top-of-the-atmosphere radiance $(I)$ in a cloudfree atmosphere is calculated using

$I=I_{\mathrm{a}}+\frac{R T}{\left(1-R S_{\mathrm{b}}\right)}$,

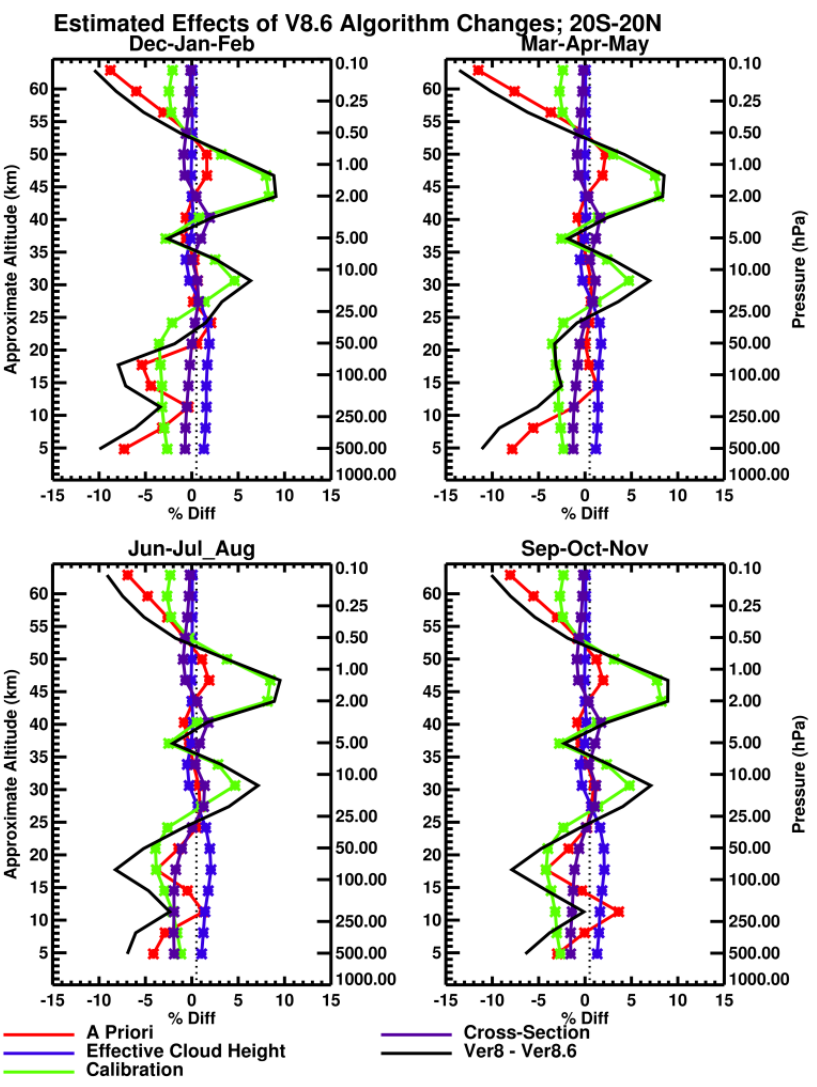

Fig. 2. Estimated effects of individual algorithm parameter changes from V8 to V8.6 of the SBUV algorithm in the tropics. The effects are estimated from a series of test retrievals replacing V8.6 parameters with those used in V8, one parameter at a time. Tests shown are for the change in a priori, cloud height, calibration and cross-section. The retrieval tests were run using N17 SBUV data in 2007. Daily zonal mean differences are shown for 3-month periods to highlight seasonal differences, which are minimal in the tropics. Final V8-V8.6 ozone profiles are shown in black. Differences in V8.6 are dominated by calibration changes in the middle stratosphere, and by a priori changes at the top and bottom of the profile. The cross-section and mean cloud height changes are smaller and tend to cancel each other below $25 \mathrm{hPa}$.

where $I_{\mathrm{a}}$ is the purely atmospheric contribution and the 2 nd term is the contribution from a Lambertian surface of reflectivity $R . T$ is the diffuse plus direct solar radiance impinging on the surface times their transmittance to the satellite, and $S_{\mathrm{b}}$ is the surface-to-atmosphere backscatter fraction. Equation (1) is inverted to estimate $R$ from Sun-normalized $331 \mathrm{~nm}$ radiances $\left(I_{331}\right)$ by

$$
R=\frac{\left(I_{331}-I_{\mathrm{a}}\right)}{\left[T+\left(I_{331}-I_{\mathrm{a}}\right) S_{\mathrm{b}}\right]} .
$$

Dave called the variable $R$ so derived the Lambert-equivalent reflectivity (LER). Radiative transfer calculations show that in the absence of aerosols LER is close to the reflectance of the surface under ambient illumination in the relevant 

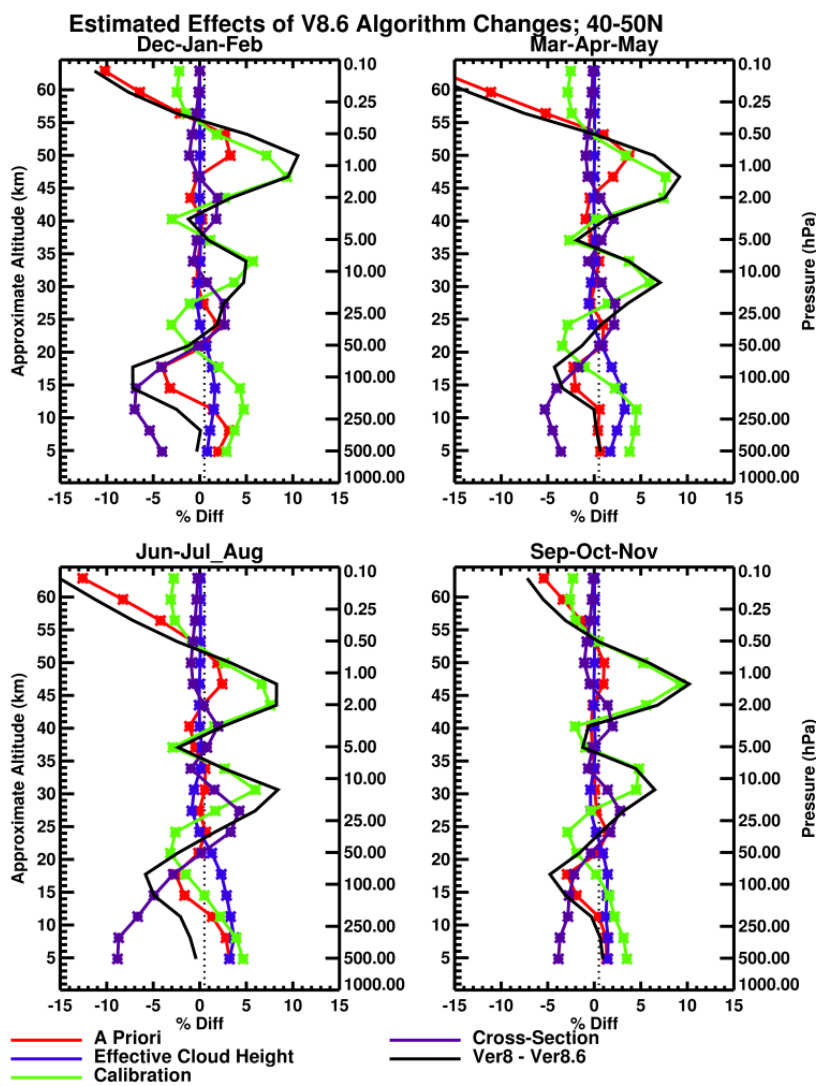

Fig. 3. Same as Fig. S4, but for the $40-50^{\circ} \mathrm{N}$ latitude band. Again, the largest differences between the V8 and V8.6 algorithms are due to the updated calibration and a priori, but the cross-section also causes notable differences below $100 \mathrm{hPa}$ at $40-50^{\circ} \mathrm{N}$. Cloudheight climatology differences vary seasonally at this latitude, with a larger influence in the NH spring-summer months.

measurement geometry. The effect of aerosol is to increase $R$, and to introduce a spectral dependence depending upon its absorptive properties (Dave, 1978).

To account for clouds the TOA radiance is calculated by independent pixel approximation (IPA) in which one assumes that the scene consists of a mixture of two noninteracting scenes:

$I=I_{\mathrm{s}}\left(R_{\mathrm{s}}, P_{\mathrm{s}}\right)\left(1-f_{\mathrm{c}}\right)+I_{\mathrm{c}}\left(R_{\mathrm{c}}, P_{\mathrm{c}}\right) f_{\mathrm{c}}$,

where $I_{\mathrm{S}}$ is the TOA radiance calculated by assuming a Lambertian surface of reflectance $R_{\mathrm{S}}$ at pressure $P_{\mathrm{S}}$, and $I_{\mathrm{c}}$ assuming an opaque Lambertian cloud of reflectance $R_{\mathrm{c}}$ at pressure $P_{\mathrm{c}}$. Since both terms are calculated using the Lambertian approximation we call this model the Mixed LER (MLER) model. We estimate $f_{\mathrm{c}}$ from $331 \mathrm{~nm}$ radiances by inverting Eq. (3), assuming $R_{\mathrm{S}}$ of $0.15, R_{\mathrm{c}}$ of 0.80 , and climatological values of $P_{\mathrm{s}}$ and $P_{\mathrm{c}}$. We use the LER model when $f_{\mathrm{c}}$ becomes negative or greater than 1 , as well as for snow/ice. Both $R$ and $f_{\mathrm{c}}$ are assumed to be wavelength $(\lambda)$ independent for computing the radiances at other wavelengths. Since the 2 nd
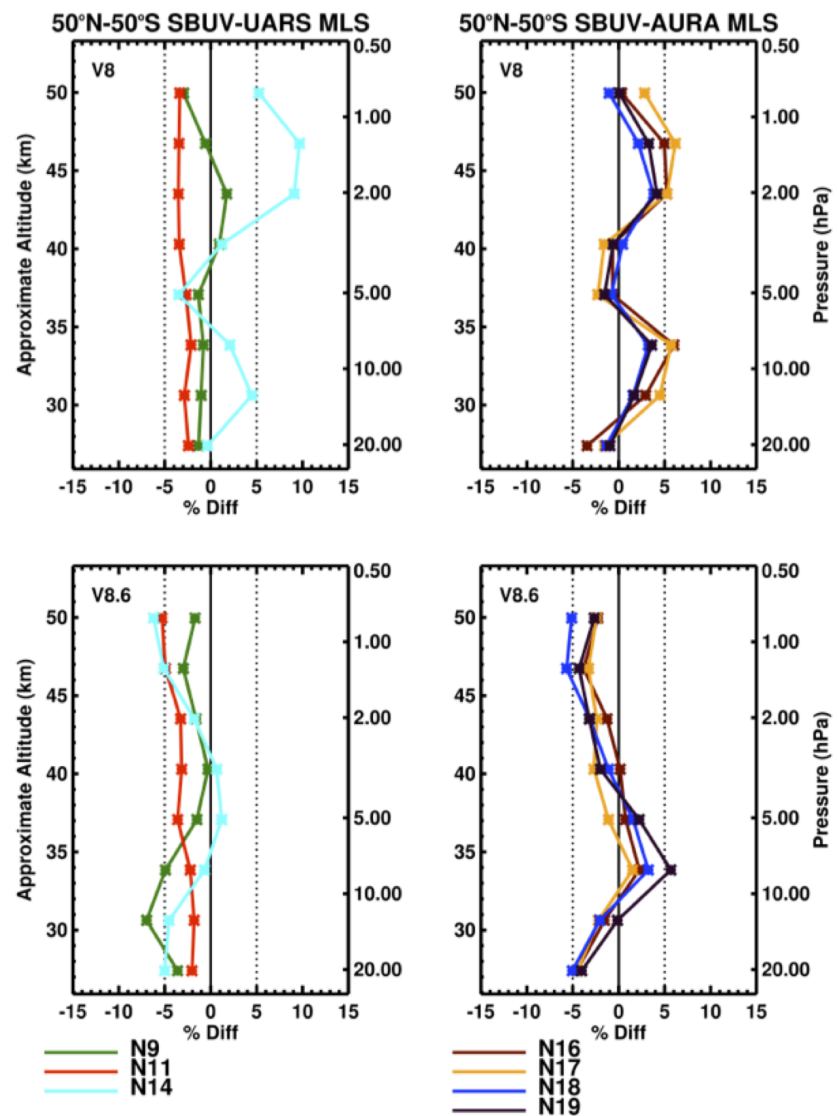

Fig. 4. SBUV minus MLS difference profiles averaged from $50^{\circ} \mathrm{N}$ to $50^{\circ} \mathrm{S}$. Top panel shows differences using Version $8 \mathrm{SBUV}$, and bottom panel shows differences using Version 8.6 SBUV. NOAAs 9/11/14 are compared to UARS MLS, and NOAAs 16/17/18/19 are compared to AURA MLS. N17 difference profiles, shown in orange in the right-side panels, can be compared with results shown in Figs. S3 and S4.

term on the right side of Eq. (3) assumes an opaque cloud, it does not account for photons scattered by the atmosphere and surface below the cloud that pass through the cloud. The MLER model accounts for this contribution through the 1st term, since the $f_{\mathrm{c}}$ derived from Eq. (3) becomes smaller than the geometrical cloud fraction for clouds with reflectance smaller than 0.8. Mie scattering calculations (Ahmad et al., 2004) show that this approach works quite well in computing the $\lambda$ dependence of TOA radiance in the presence of clouds.

As in $\mathrm{V} 6, T$ and $S_{\mathrm{b}}$ are tabulated, while $I_{\mathrm{a}}$ is calculated as the sum of two terms: the single scattering term is calculated online using a spherical radiative transfer code (Bhartia et al., 1996), and the multiple scattering term is obtained by table look-up. Since the multiply-scattered and reflected components of radiances (MSR) vary largely with total ozone and have a weak dependence on ozone profile, the MSR tables are created using the 21 TOMS standard profiles discussed earlier. Though in V6 we made no correction to these radiances 
for the difference between the standard profile and the retrieved profile, we now apply a first-order Taylor series correction for this difference using Jacobians that are similarly tabulated. We compute the radiances at $0.1 \mathrm{~nm}$ intervals and then band-average them to create the tables for the $1.1 \mathrm{~nm}$ instrument bandpass. Though this method was developed for the slow computers of earlier years, we have not seen any reason to change it since it produces accurate radiances and allows us to reprocess the entire SBUV record in a short time.

\subsection{Inverse model}

The inverse model is based on the optimum estimation formula of Rodgers (1976), designed for retrievals where the numbers of layers are larger than the number of wavelengths:

$$
\begin{aligned}
\hat{\mathbf{X}}_{n+1}= & \mathbf{X}^{\mathrm{a}}+\mathbf{S K}_{n}^{T}\left(\mathbf{K}_{n} \mathbf{S} \mathbf{K}_{n}^{T}+\mathbf{S}_{\varepsilon}\right)^{-1} \\
& {\left[\mathbf{Y}-\mathbf{Y}_{n}-\mathbf{K}_{n}\left(\mathbf{X}^{\mathrm{a}}-\hat{\mathbf{X}}_{n}\right)\right], }
\end{aligned}
$$

where $\hat{\mathbf{X}}_{n}$ is the state vector (ozone profile) retrieved in the $n$th iteration; $\mathbf{Y}$ is the measurement vector; $\mathbf{K}$ is the Jacobian $\left|\frac{\partial y}{\partial x}\right| ; \mathbf{X}^{\mathrm{a}}$ is the a priori profile; $\mathbf{S}$ is the covariance matrix, representing the assumed variation of the true profiles with respect to a priori; and $\mathbf{S}_{\varepsilon}$ is the covariance matrix of measurement errors. (We use lowercase to represent the elements of a matrix and uppercase for the matrix). In V6 we used the logarithm of layer ozone as $x$ to prevent layer ozone from becoming negative. However, this can produce a systematic bias in situations where the error in the retrieved value is larger than the value itself. Such situations typically occur in ozone hole conditions. Therefore, starting with V8, we assume that $x$ is the layer column ozone density.

The state vector $\mathbf{X}$ consists of ozone in 80 layers of equal $\log$ pressure, 20 layers per decade of pressure, covering 1 to $10^{-4} \mathrm{~atm}(1 \mathrm{~atm}=1013.25 \mathrm{hPa})$, plus a top layer that extends to zero atm. We use these fine layers for quadrature accuracy. Since the vertical resolution of the retrieved profiles is much coarser, we report them in 21 layers by combining ozone in 4 layers to reduce from 80 to 20 layers plus the top layer. We shall call them SBUV layers. The pressure at the bottom of SBUV layer $L$ is $10^{-(L-1) / 5} \mathrm{~atm}$ - each layer being $\sim 3.2 \mathrm{~km}$ thick. We also provide ozone mixing ratio on standard pressure levels (Fig. 5).

The measurement vector $\mathbf{Y}$ consists of $N$ values, where $N=-100 \log _{10} I$ and $I$ is the Sun-normalized radiance. $N$ values are a measure of atmospheric attenuation, expressed in tenths of decibels; $1 \mathrm{~N}$ value increase represents a $2.3 \%$ decrease in $I$. Depending upon the instrument and solar zenith angle, the dimension of $\mathbf{Y}$ varies from 6 to 9 . The longest SBUV band centered at $340 \mathrm{~nm}$ wavelength is currently not used. Since $331 \mathrm{~nm}$ is used to estimate $R / f_{\mathrm{c}}$, as described in Sect. 3.1, it is not included in Y. For Nimbus-4/BUV and Nimbus-7/SBUV the shortest wavelength, centered at $253.7 \mathrm{~nm}$, was contaminated by NO gamma-band emission

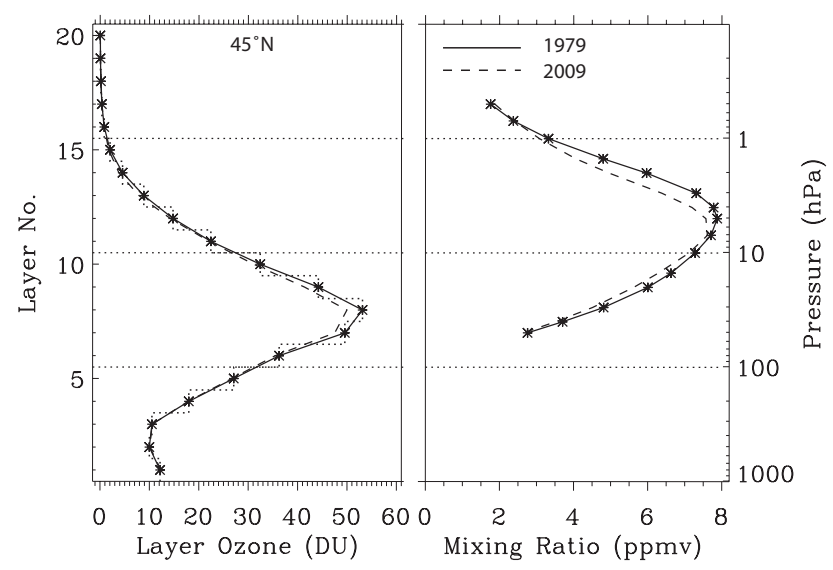

Fig. 5. Left plot shows the definition of 20 SBUV layers in pressure coordinates. The symbols show the layer midpoints (in logp). The right plot shows the 15 pressure levels where ozone mixing ratios are provided in the monthly zonal mean files. The annual mean ozone profiles at $45^{\circ} \mathrm{N}$ latitude show significant decrease in ozone at most pressure levels over 3 decades.

(McPeters, 1989). Though this wavelength was changed to $252 \mathrm{~nm}$ in subsequent instruments to avoid the contamination, the behavior of several NOAA SBUV/2 instruments at this wavelength has been erratic. To maintain long-term consistency we do not use this wavelength in the present algorithm. The longest wavelength used varies from $302 \mathrm{~nm}$ at small solar zenith angles (SZAs) to $317.5 \mathrm{~nm}$ at large SZAs. This was done to minimize the effect of smoke and mineral dust aerosols that have very high absorption in the UV (Torres and Bhartia, 1999).

Since SBUV data are typically analyzed by computing the monthly zonal mean (MZM) of ozone, we considered retrieving MZM ozone directly using the MZM of $N$ values. Though the $N$ values vary almost linearly with layer ozone at most SBUV wavelengths, at some wavelengths (e.g., $302 \mathrm{~nm}$ ) the non-linearity becomes too large for accurate retrieval using this method. So, while we continue to do individual profile retrievals, we have optimized the algorithm for estimating accurate MZMs by constructing the $\mathbf{S}$ matrix to approximate the variability of MZMs rather than of individual profiles. Aura MLS data show that the fractional standard variation of MZM anomalies (difference from climatology) is roughly independent of altitude, and the variations are correlated in adjacent layers. Hence in constructing the $\mathbf{S}$ matrix we assume that layer ozone has a constant fractional variation $(\sigma)$ in all layers with a correlation length of 12 layers $(\sim 10 \mathrm{~km})$, which gives $S(i, j)=\sigma^{2} x_{i}^{\mathrm{a}} x_{j}^{\mathrm{a}} e^{-|i-j| / 12}$, where $i$ and $j$ are layer numbers. We also assume that the measurement uncertainties $\left(\sigma_{\varepsilon}\right)$ are uncorrelated, independent of wavelength or signal level, which gives $\mathbf{S}_{\varepsilon}=\sigma_{\varepsilon}^{2} \mathbf{I}$, where $\mathbf{I}$ is the unit matrix. In this formulation the algorithm becomes very similar to the Twomey algorithm (Rodgers, 1990; Twomey, 1963) with $\gamma=\left(\sigma_{\varepsilon} / \sigma\right)^{2}$. We have selected 
$\gamma$ of 0.754 (or $4 \times 10^{-4}$ if the radiance error is converted from $N$ value to fractional error) by examining the sensitivity of the algorithm to expected errors in instrument calibration. Since we retrieve individual profiles rather than the MZM we assume rather large values for $\sigma(=0.5)$ and $\sigma_{\varepsilon}(=0.43 N$, or $1 \%$ of radiance) in the processing software for detecting anomalous measurements. However, only the value of $\gamma$, and to a lesser extent the correlation length, affects the actual retrieval.

We note that it is possible to optimize the SBUV algorithm for the retrieval of short-term variability by constructing $\mathbf{S}$ and $\mathbf{S}_{\varepsilon}$ differently. Since short-term $\sigma$ varies by more than an order of magnitude with altitude, latitude, and season the $\mathbf{S}$ matrix should reflect this variation. Similarly, the $\mathbf{S}_{\varepsilon}$ matrix should reflect the instrument and cloud-caused noise that varies with wavelength and signal level. Such algorithms have been developed for other UV instruments (Liu et al., 2005, 2010).

\subsection{Information content}

Rodgers (2000) discusses a variety of methods to characterize the information content of atmospheric profiles retrieved using inverse methods. However, his focus is largely on individual measurements rather than on the ensemble mean of retrieved profiles. In the following we have adapted his concepts for understanding the information contained in the MZM of ozone profiles calculated by averaging individual SBUV profiles in order to provide guidance on how best to use these data for comparison with other instruments, trend analysis, and model validation.

\subsubsection{Smoothing kernels}

In the absence of measurement errors the relationship between the true profile $(\mathbf{X})$ and the retrieved profile $(\hat{\mathbf{X}})$ can be expressed as

$\hat{x}_{i}-x_{i}^{\mathrm{a}}=\sum_{j} w_{i j}\left(x_{j}-x_{j}^{\mathrm{a}}\right)$

$\mathbf{W}=\mathbf{S K}_{n}^{T}\left(\mathbf{K}_{n} \mathbf{S} \mathbf{K}_{n}^{T}+\mathbf{S}_{\varepsilon}\right)^{-1} \mathbf{K}_{n}$.

W acts as a low-pass filter to convert the true anomaly (difference between the true profile and SBUV-assumed climatology) into the retrieved anomaly. Since the elements of $\mathbf{W}$ can have large positive and negative values and its rows do not sum to 1, Eq. (5) produces a weighted sum rather than the average of the true anomalies; therefore, we shall call them integrating kernels (IKs). One can construct other filters depending on one's intended application. To get the more traditional bell-shaped filters, one can rewrite Eq. (5) as

$$
\frac{\left(\hat{x}_{i}-x_{i}^{\mathrm{a}}\right)}{\hat{x}_{i}}=\sum_{j} a_{i j} \frac{\left(x_{j}-x_{j}^{\mathrm{a}}\right)}{\hat{x}_{j}}, \text { where, } a_{i j}=w_{i j} \frac{\hat{x}_{j}}{\hat{x}_{i}} \text {. }
$$

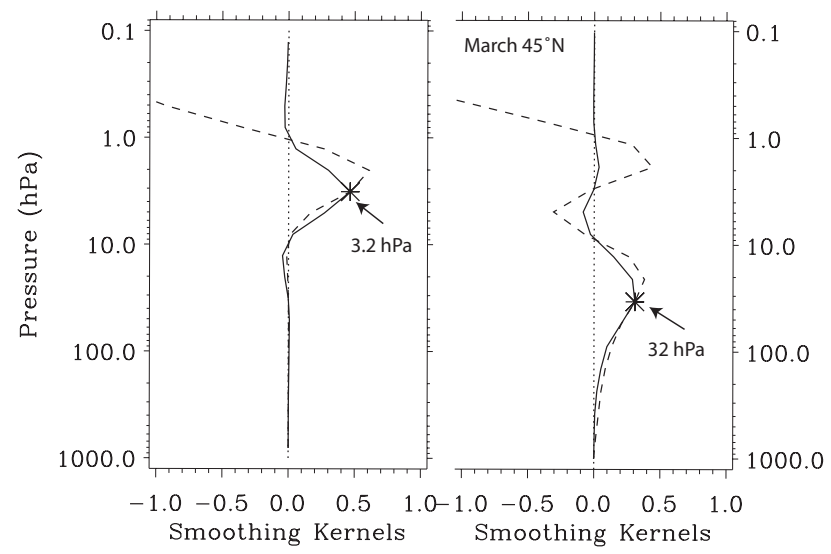

Fig. 6. SBUV smoothing kernels at 3.2 and $32 \mathrm{hPa}$ for March at $45^{\circ} \mathrm{N}$. The solid lines apply to fractional changes in layer ozone and the dashed line to absolute changes. We call them averaging and integrating kernels respectively. Though quite different in shape the two kernels produce mathematically the same result.

The matrix A with elements $a_{i j}$ smoothes fractional anomalies. For consistency with previous usage of this term we shall call them averaging kernels (AKs), even though the rows of A do not sum to exactly 1 . To smooth mixing ratio (MR) anomalies one can replace $x_{i}$ with $m_{i} p_{i}$ in Eq. (5), where $m_{i}$ is the average MR in layer $i$ and $p_{i}$ is the pressure at the midpoint of the layer. The elements of the smoothing matrix in this case become $w_{i j} p_{j} / p_{i}$. We refer to all such filters as smoothing kernels (SKs). Since SKs of a variety of different shapes can be created simply by coordinate transformation, the shapes of the SKs are obviously not important. However, the diagonal elements of SKs are invariant under such transformations, so they are more robust and easier to interpret. We will discuss them in the next section.

Figure 6 compares two forms of SKs that we have found most useful. The AKs are useful for smoothing individual profiles in the upper stratosphere, where the kernels are well defined and are centered at the correct pressure levels. We provide the AKs for all the SBUV layers for different latitudes and SZA in the attached Supplement (Figs. S3 and S4). The IKs are more useful for smoothing layer ozone amounts, particularly in the lower layers where the layers need to be combined to produce useful results from SBUV. They are also useful for analyzing MZMs. Since $\mathbf{W}$ is nearly independent of $\mathbf{X}-\mathbf{X}^{\mathrm{a}}$, one can smooth MZM anomalies using the following expression:

$\left(\overline{\hat{\mathbf{X}}}-\mathbf{X}^{\mathrm{a}}\right)=\overline{\mathbf{W}}\left(\overline{\mathbf{X}}-\mathbf{X}^{\mathrm{a}}\right)$,

where the horizontal bars represent MZM. For this reason we provide $\bar{W}$ on the MZM files. (SBUV orbital files contain the more familiar AKs. Note that for historical reasons some SBUV documents (Flynn, 2007) may refer to $\mathbf{W}$ as AK and $A$ as fractional AK. Our use of terms IK and AK for these kernels is designed to eliminate this confusion.) 


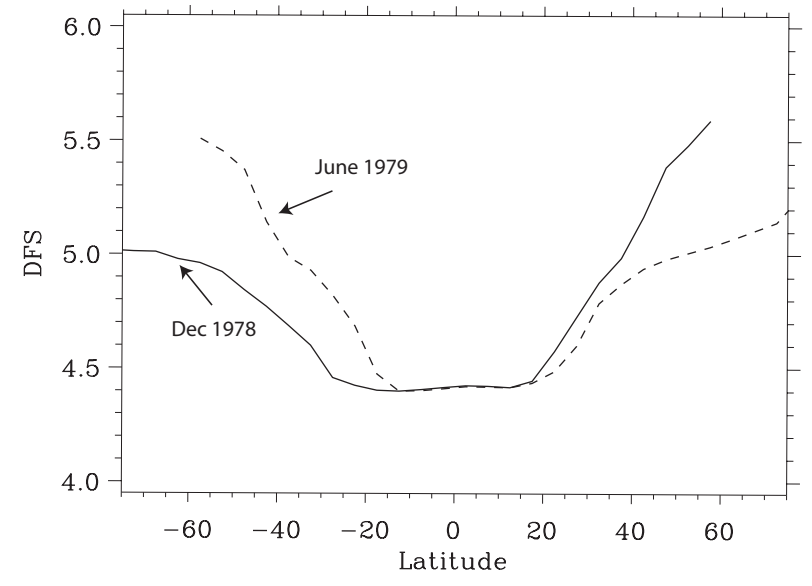

Fig. 7. Typical latitude dependence of the degrees of freedom of signal (DFS). Variations in DFS are partly caused by change in solar zenith angle that changes the number of wavelengths used in the algorithm from a minimum of 6 to a maximum of 9 , and partly by change in tropopause height: the higher the ozone density peak, the lower the DFS. Both effects combined produce smallest DFS in the tropics.

\subsubsection{Degrees of freedom of the signal (DFS)}

Rodgers (2000) refers to the sum of the diagonal elements of the averaging kernels as DFS. DFS values plotted in Fig. 7 provide an estimate of the independent pieces of information that the algorithm is capable of retrieving. Note that DFS cannot exceed the number of wavelengths used, which varies from 6 at low SZAs to 9 at large SZAs. Figure 8 shows the diagonal elements of $\overline{\mathbf{W}}$ (layer DFS). Since $1 / w_{i i}$ is roughly the vertical resolution of the retrieved profile in units of layers, we can convert them into $\mathrm{km}$ by multiplying with 3.2. Figure 9 shows the SBUV vertical resolution derived this way. This method does not require that the smoothing kernels have Gaussian shapes. We have chosen the layering scheme for reporting SBUV profiles such that the maximum DFS of a layer is $\sim 0.5$, which provides roughly two data points per resolution element to meet Nyquist sampling criterion.

Figure 9 shows that the vertical resolution of SBUV profiles varies considerably with height. This complicates the analysis and interpretation of SBUV data. The recommended procedure for comparing SBUV data with models and other measurements is to compare anomalies smoothed using Eqs. (5)-(8). However, as the DFS of a layer goes down (resolution gets worse) interpretation of SBUV data gets increasingly difficult. An alternative is to combine multiple layers to create thicker layers. However, the advantage of doing so may or may not be significant. Firstly, when layers $i_{1}$ through $i_{2}$ are combined the DFS of the combined layer (assuming that the fractional standard deviation of ozone is independent of layer number) is given by $\frac{\sum_{i=i_{1}}^{i_{2}} x_{i} \sum_{j=i_{1}}^{i_{2}} w_{i j}}{\sum_{i_{1}}^{i_{2}} x_{i}}$. Because

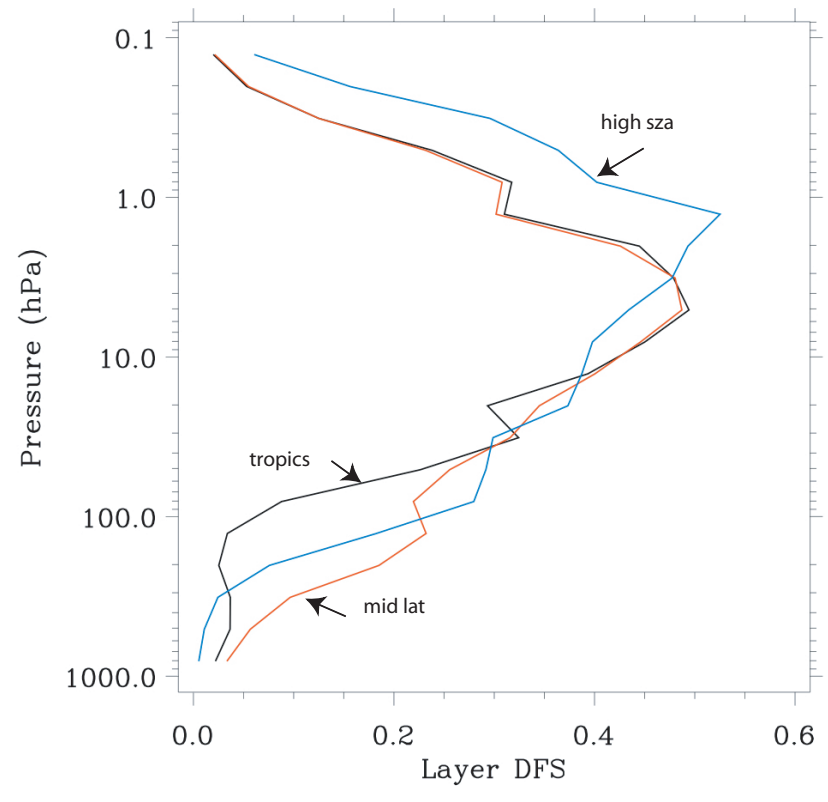

Fig. 8. Variation of layer DFS (LDFS) with height. LDFS provides the fraction of ozone change in a layer that would appear in the same layer in the retrieved profile. The vertical resolution of the retrieved profile is $\sim 3.2 / \mathrm{LDFS}$ in $\mathrm{km}$, showing that the vertical resolution varies from $\sim 6 \mathrm{~km}$ near $3 \mathrm{hPa}$ to $\sim 15 \mathrm{~km}$ in the lower stratosphere. Lower stratospheric LDFS is largely determined by tropopause height, and the mesospheric LDFS by SZA.

of the weighting by $x_{i}$, this is typically not much larger than the DFS of the layer for which $x_{i}$ is the largest. Secondly, thicker layers usually have smaller fractional variability. So the signal-to-noise ratio may not improve, and may even get worse, when layers are combined.

\subsubsection{Column integrating kernels}

From Eq. (5) it is easy to construct smoothing kernels $\left(\mathbf{W}^{\mathrm{c}}\right)$ for the anomalies of any partial column. For the partial ozone column obtained by summing layers $i_{1}$ through $i_{2}$ the elements of $\mathbf{W}^{\mathrm{c}}$ are given by $w_{j}^{\mathrm{c}}=\sum_{i=i_{1}}^{i_{2}} w_{i j}$. For a perfect retrieval $\mathbf{W}^{\mathbf{c}}$ should be 1 in layers $i_{1}$ though $i_{2}$ and zero elsewhere. Though, strictly speaking, this does not occur for any layer combination, the IK for total ozone comes very close to the ideal (Fig. 10). Note that this occurs despite the fact that the DFS of the lower SBUV layers is quite small. The reason is that while the algorithm does not have the vertical resolution to distinguish between tropospheric and stratospheric changes, the measured radiances are quite sensitive to tropospheric ozone variability. To explain the measurements the algorithm distributes the tropospheric changes over a wide range of altitudes to minimize the fractional deviation of the retrieved profile from the a priori profile. 


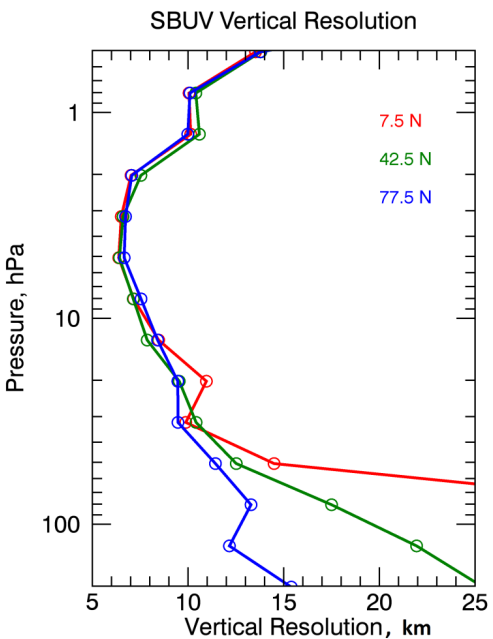

Fig. 9. SBUV vertical resolution estimated from the diagonal elements of the SBUV averaging kernels for three different latitude zones: tropics $\left(5-10^{\circ} \mathrm{N}, \mathrm{SZA}=27^{\circ}\right)$, mid-latitudes $(40$ $\left.45^{\circ} \mathrm{N}, \mathrm{SZA}=26^{\circ}\right)$, and high latitudes $\left(75-80^{\circ} \mathrm{N}, \mathrm{SZA}=57.5^{\circ}\right)$ for NOAA-17 for July 2004. The SBUV vertical resolution is about 6-7 $\mathrm{km}$ between 10 and $2 \mathrm{hPa}$ and degrades above and below this range. The vertical resolution is similar for all latitude bands between $20 \mathrm{hPa}$ and $0.5 \mathrm{hPa}$. Below $20 \mathrm{hPa}$ the SBUV vertical resolution in the tropics decreases sharply, due to fewer wavelengths used to retrieve ozone at small SZAs and the higher altitude of the ozone density peak. However, loss of vertical resolution does not affect the quality of total and partial column ozone retrievals in the tropics or elsewhere.

\section{Error analysis}

Algorithmic errors in retrieved profiles from remote sensing instruments such as SBUV tend to be spatially and temporally correlated. Therefore, as data are averaged, truly random errors such as instrument noise quickly become insignificant compared to non-random errors. On the other end of the error spectrum are systematic errors that do not vary significantly from year to year. Typical examples are errors in ozone absorption cross-section or in various climatologies used in the retrieval. Though biases produced by such errors often get a lot of attention, they are usually of little importance for the study of interannual variability and trends from a single instrument type. However, they do become important when combining data from different instruments. Since such complexity cannot be handled simply by providing accuracy and precision numbers we discuss below errors that are specific to particular applications.

\subsection{Errors in deriving interannual variability and trend}

From Eq. (5), in the absence of instrument error, the error in MZM anomaly (deviation from long-term mean of SBUV

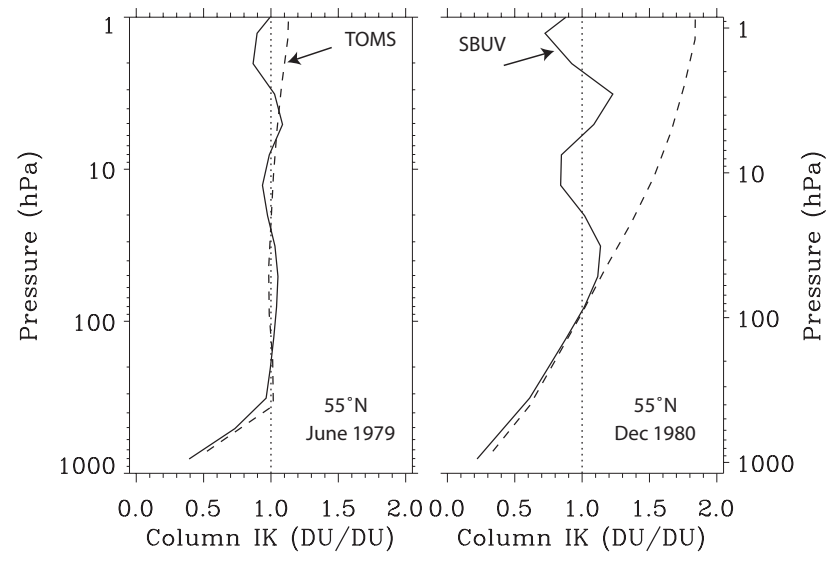

Fig. 10. Comparison of Nimbus-7 SBUV and TOMS integrating kernels (IKs) for ozone column. Column IK provides the fraction of $\mathrm{O}_{3}$ change in a layer that would appear in the total $\mathrm{O}_{3}$ column of the retrieved profile. A value of 1 represents ideal sensitivity. Though TOMS uses longer wavelengths than SBUV they both have similar IKs in the summer months when SZA is small. But at larger SZAs ( $55^{\circ} \mathrm{N}$ in December) TOMS become over-sensitive to $\mathrm{O}_{3}$ variations at higher altitudes, causing increased noise in retrieved total $\mathrm{O}_{3}$. Since the TOMS algorithm uses climatological profiles to estimate total $\mathrm{O}_{3}$, this also causes biases when the true profile deviates from them.

data themselves, not from a priori) is given by

$\delta \hat{\mathbf{X}}=(\overline{\mathbf{W}}-\mathbf{I}) \Delta \mathbf{X}$.

The covariance matrix of this error, called smoothing error, is given by $(\overline{\mathbf{W}}-I) \mathbf{S}_{z}(\overline{\mathbf{W}}-\mathbf{I})^{T}$, where $\mathbf{S}_{z}$ is the covariance matrix of the true MZM anomalies of ozone in SBUV layers. We provide the square root of the diagonal elements of these errors in the SBUV MZM files. To do this calculation we use $\mathbf{S}_{z}$ estimated from Aura/MLS and ozonesonde data. Figures 11 and 12 show estimated errors in retrieved profiles and total ozone respectively for some typical cases.

In addition to smoothing errors one also may have errors in measuring and computing the radiances. The contribution of these errors to MZM anomaly is given by $\overline{\mathbf{G}} \varepsilon_{N}$, where $\varepsilon_{N}$ is the MZM anomaly of $N$ value errors, and $\mathbf{G}$ is given by

$\mathbf{G}=\mathbf{S} \mathbf{K}_{n}^{T}\left(\mathbf{K}_{n} \mathbf{S} \mathbf{K}_{n}^{T}+\mathbf{S}_{\varepsilon}\right)^{-1}$.

To apply Eq. (10) to estimate profile errors one needs to know $\varepsilon_{N}$. Of course, if one knew $\varepsilon_{N}$ one would have corrected the $N$ values. So the primary value of $\mathbf{G}$ is to assess if a model of instrument behavior derived from other means, including comparison with other datasets, is consistent with the measurement. A useful way to do so is to look at the time dependence of the final residuals $\left(\mathbf{r}_{\mathbf{f}}\right)$, which are defined as the difference between measured $N$ values and those calculated from the retrieved profile. The following expression provides 


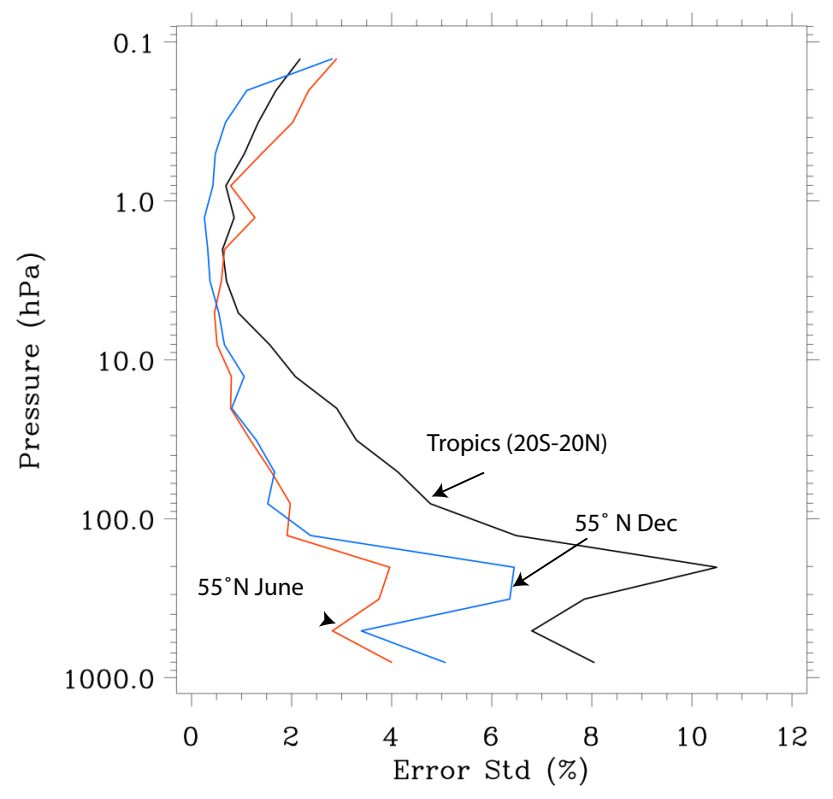

Fig. 11. Smoothing error $(1 \sigma)$ in estimating MZM of layer ozone. Larger errors in the tropical lower stratosphere are caused by smaller layer DFS and larger year-to-year fractional variability due to QBO. The errors shown are typically the largest source of error in estimating $\mathrm{MZM} \mathrm{O}_{3}$ anomalies from an SBUV instrument.

the relationship between the two:

$\mathbf{r}_{\mathrm{f}}=\left(\mathbf{I}-\mathbf{K}_{n}^{*} \mathbf{G}\right) \varepsilon_{N}$,

where $\mathbf{G}$ is calculated from Eq. (10) using $\mathbf{K}$ whose column is set to zero if the corresponding wavelength is not used in the retrieval, while $\mathbf{K}^{*}$ is calculated at all wavelengths to provide the residuals at all wavelengths. For an assumed $\varepsilon_{N}$ one can calculate the residuals using Eq. (11) and compare with retrieved values to see if they agree. Figure 13 shows the effect of a linearly varying error in $N$ values on retrieved $\mathrm{O}_{3}$ and residuals estimated using Eqs. (10) and (11). Analysis of such residuals has been very useful in detecting and assessing SBUV instrument errors (DeLand et al., 2012).

\subsection{Systematic errors/biases}

There are several sources of systematic errors that can create time-independent (but month- and latitude-dependent) bias in the SBUV retrieved profiles. They include errors in a priori profiles, in measured and calculated $N$ values, and in various climatologies used in the forward model. To estimate such errors quantitatively it is necessary to compare with sensors with higher accuracy than SBUV. Since Kramarova et al. (2013b) and Labow et al. (2013) discuss such comparisons, in this section we will provide just an overview of the errors involved.

An error $\delta \mathbf{X}^{\mathrm{a}}$ in a priori profile introduces a bias in the retrieved profile given by $\delta \hat{\mathbf{X}}=(\mathbf{I}-\overline{\mathbf{W}}) \delta \mathbf{X}^{\mathrm{a}}$. Since $(\mathbf{I}-\mathbf{W})$

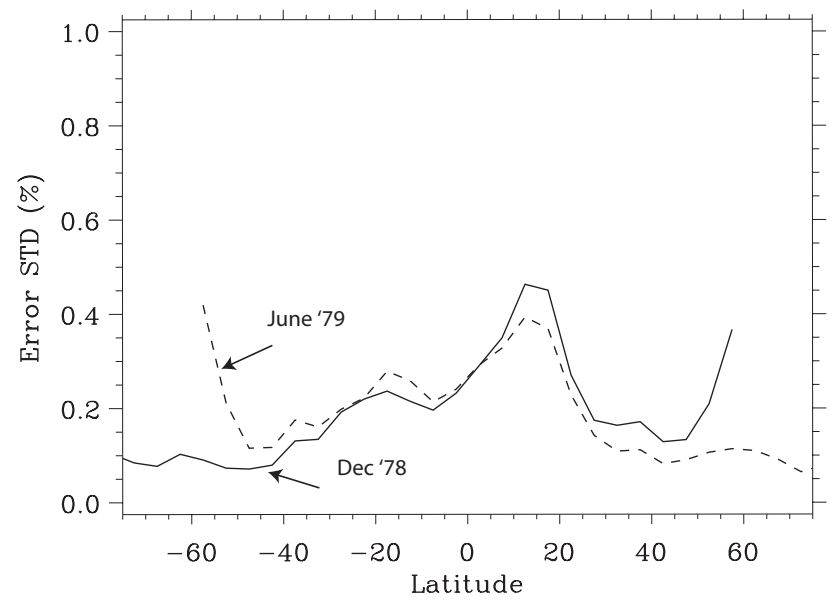

Fig. 12. Typical latitude dependence of smoothing error $(1 \sigma)$ in estimating MZM of total column $\mathrm{O}_{3}$ from SBUV. These errors are caused by reduced sensitivity of the algorithm to tropospheric ozone variations seen in Fig. 6, which gets worse at larger SZAs. Larger errors in northern tropics are caused by larger interannual variability of tropospheric ozone. Since they are based on a very limited number of ozonesonde stations, they may not be reliable.

acts as a high-pass filter, low vertical resolution errors in $\mathbf{X}^{\mathrm{a}}$, such as biases that vary slowly with altitude, are filtered out by the algorithm. By contrast high vertical resolution errors, such as incorrect tropopause height or mixing ratio peak, will affect the retrieval. Though such errors are reduced by providing SBUV profiles in $\sim 3.2 \mathrm{~km}$-thick layers, they are not eliminated completely. For example a layer with DFS of 0.3 will transmit $70 \%$ of the bias in $\mathbf{X}^{\mathrm{a}}$ in that layer to the retrieved profile. But if the fractional bias is the same in adjacent layers its impact on the retrieved profile is reduced.

Errors in measured $N$ values include calibration errors that typically do not vary with latitude, but may include other errors that do, e.g., non-linearity and straylight. Since SBUV uses a double monochromator with a single detector the spectral and spatial straylight errors are small. For more details on the characterization of SBUV instruments see DeLand et al. (2012).

Since the UV ozone absorption cross-section varies with temperature, an error in the assumed temperature climatology will introduce an error when calculating the $N$ values. This error is minimized for SBUV since SBUV does not use measurements in the Huggins ozone absorption band where the temperature sensitivities are large (Table 1). Other sources of error in computing the $N$ values include polar mesospheric clouds (PMCs) (DeLand et al., 2003), stratospheric aerosols produced by volcanic eruptions (Torres and Bhartia, 1995), volcanic $\mathrm{SO}_{2}$ (McPeters, 1993), and UVabsorbing aerosols, which include ash, smoke, and desert dust (Torres and Bhartia, 1999).

Thomas et al. (1991) developed a method to detect PMC from Nimbus-7 SBUV measurements and concluded that the 

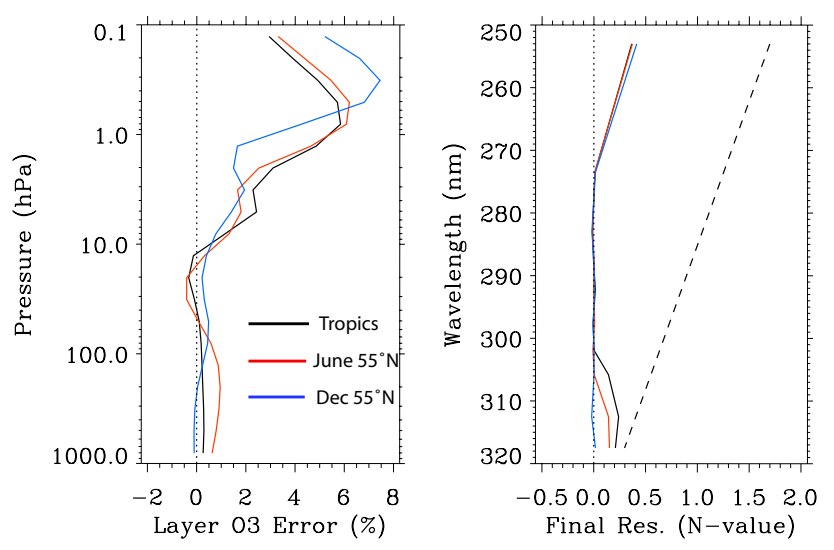

Fig. 13. Left panel shows error in layer $\mathrm{O}_{3}$ caused by $0.05 \%$ per nm linearly varying error in NOAA-17 SBUV radiances, assuming zero error at $331 \mathrm{~nm}$ (where ice radiances are used to stabilize instrument calibration) and $4 \%$ error at $252 \mathrm{~nm}$ (shown as dashed line on the right panel in $N$ value unit). At higher altitudes the errors vary with SZA due to change in layer DFS shown in Fig. 5. Right panel shows the final residuals (difference from measured and calculated radiances) in $N$ value $(1 N=-2.3 \%)$. The residuals are non-zero at wavelengths not used by the algorithm allowing one to monitor such errors.

error in ozone profile derived from the V6 algorithm can be as large as $10 \%$. Analysis of results from the V8.6 algorithm by comparing profiles affected with PMC with unaffected profiles indicates that this effect is typically in the 2$3 \%$ range. The reason for this apparent improvement has not been investigated.

Volcanic $\mathrm{SO}_{2}$ has a very short lifetime and therefore does not affect SBUV MZM O $\mathrm{O}_{3}$ profiles and total $\mathrm{O}_{3}$. But $\mathrm{H}_{2} \mathrm{SO}_{4}$ aerosols produced from $\mathrm{SO}_{2}$ can linger for several years. These aerosols do affect SBUV measurements. During the $42 \mathrm{yr}$ record of SBUV measurements there have been two large volcanic eruptions (El Chichon, April, 1982; Mt. Pinatubo, June, 1991) that produced aerosol layers at altitudes higher than $25 \mathrm{~km}$. The effects of these aerosols on SBUV and TOMS radiances and retrieved ozone products have been analyzed in detail (Bhartia et al., 1993; Torres and Bhartia, 1995; Torres et al., 1995). These analyses show that the effect of stratospheric aerosols on BUV radiances is very sensitive to where the aerosols are located with respect to the ozone density peak; aerosols above the density peak affect the shorter wavelengths more than the longer wavelengths. As a result high-altitude aerosols can produce large errors in ozone profile but relatively small error in total ozone. This allowed us to develop a scheme to flag the most badly contaminated data. However, the residual errors can still be large, so several years of SBUV data taken after these two eruptions are typically not used in trend analysis. Our preliminary analysis indicates that the effect of these aerosols remains similar in the V8.6 algorithm, so we still recommend not using 2$3 \mathrm{yr}$ of SBUV profile data after the eruption. We find that the variations of errors with latitude and solar zenith angles for a given aerosol extinction (AE) profile is so large that to make quantitative estimates of the errors one needs detailed knowledge of the variations of AE profiles with latitude and time. Since such results are now available from aerosol global transport models, we plan to use them to better quantify the effect of these aerosols on the V8.6 algorithm and possibly remove their effects when the aerosols are more dispersed and move to lower altitudes.

V8 algorithm was specifically designed to minimize the effect of tropospheric aerosols by carefully selecting the wavelengths that were not significantly affected by these aerosols. This caused us to use a variable number of wavelengths in the retrieval, as discussed before. Comparison of SBUV with TOMS, which is sensitive to these aerosols (Torres et al., 1998), indicate that the SBUV wavelength selection works well.

\subsection{Diurnal variation of ozone}

Here we need to consider an effect that is unique to the SBUV/2 instruments on NOAA satellites. Though these satellites were launched in nominal Sun-synchronous orbits, they measured at a fixed local time at any given latitude only over short time periods (1-2 yr); the local times of measurements drifted over longer time periods (McPeters et al., 2013). Since V8 data were released, a number of studies have been published showing that there is significant daytime variation of ozone in the upper stratosphere (Haefele et al., 2008; Huang et al., 2010; Sakazaki et al., 2013, and the references therein). However, there remains a large degree of uncertainty in the size and phase of these variations. The Haefele et al. (2008) study indicates considerable seasonal variation not seen by others, while Sakazaki et al. (2013) suggest considerable latitudinal variation, and changes that extend lower into the atmosphere than those seen by others. Models and measurements also disagree significantly. Some instrument teams are currently reanalyzing their data to see if some of these discrepancies can be resolved. An international team (http://www.issibern.ch/teams/ozonetrend/) has been assembled to look into this problem.

One of the impacts of the diurnal variation is on how we inter-calibrate SBUV instruments in orbits with different equator-crossing times (ECTs). In V8, we used overlap comparisons between instruments to estimate inter-instrument calibration biases. However, we did not consider diurnal effects; therefore, such effects were treated as calibration errors. In V8.6 we use "no-local-time-difference" overlap comparisons to establish the instrument inter-calibration (DeLand et al., 2012). Thus, ozone diurnal variations are preserved in the V8.6 SBUV dataset. Since the long-term ozone records from various instruments - including Umkehr, ground-based microwave radiometers, limb emission, limb scattering, solar, lunar and stellar occultation, and lidars consist of measurements taken at all different solar times, 


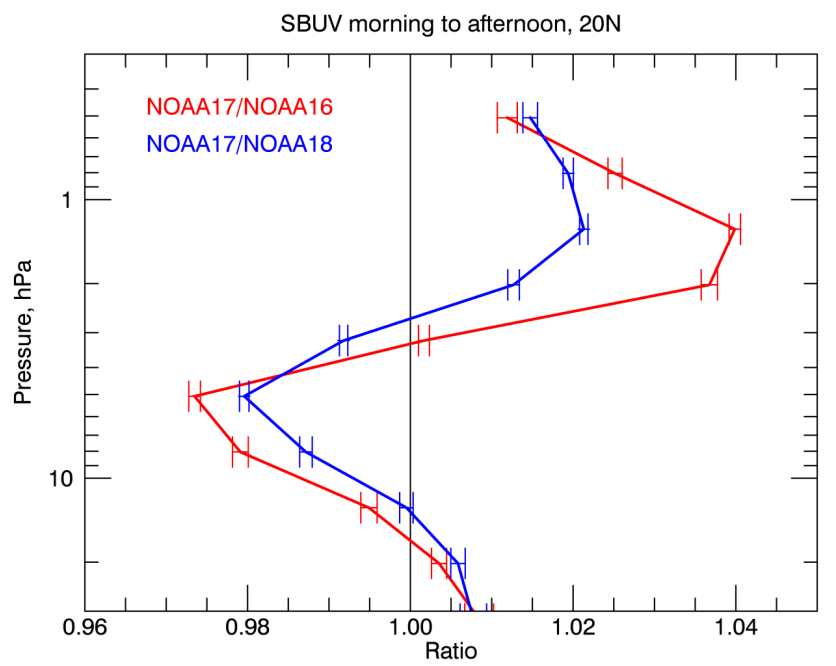

Fig. 14. Vertical profiles of the ratio between morning and afternoon SBUV measurements. NOAA-16/17 data are from 20022005, when NOAA-16 was in 14:00 equator-crossing time (ECT) orbit and NOAA-17 in 10:30 ECT; NOAA-17/18 data are from 2005-2009, when NOAA-18 was in 13:30 ECT. Error bars indicate the standard error of the mean $(\sigma / \sqrt{N})$. The 2-3\% ozone differences changing sign around $\sim 3 \mathrm{hPa}$ are qualitatively consistent with the diurnal variations measured by the NDACC microwave radiometer (MWR) at Mauna Loa (Alan Parrish, private communication).

diurnal effects must be accounted for when analyzing these data. As with QBO and solar cycle, one can use some empirical method to do so, or one can use model results. For SBUV one also needs to consider how the true diurnal variation may be distorted by the smoothing kernels, as it is for the QBO (Kramarova et al., 2013a). Figure 14 provides an estimate of the size of these variations by comparing ozone profiles derived from two SBUV instruments that measured at different local times. These results show that for the SBUV data taken between 10:00 and 14:00 LT the effect is small. However, it is not known how these effects vary with latitude and season.

\section{Results}

Since this paper focuses on the SBUV algorithm rather than on validation and data interpretation, we will limit our discussion of the SBUV results to just the NOAA-17 SBUV/2 instrument that had good overlap with Aura/MLS. Two companion papers (Kramarova et al., 2013b; Labow et al., 2013) provide more detailed comparisons and validation with ground-based sensors.

Aura/MLS has provided one of the most comprehensive datasets (Waters et al., 1999) of ozone profiles currently available to compare with SBUV. These datasets have been extensively compared with other sensors (Froidevaux et al., 2008) and their quality is well understood (Livesey et al.,
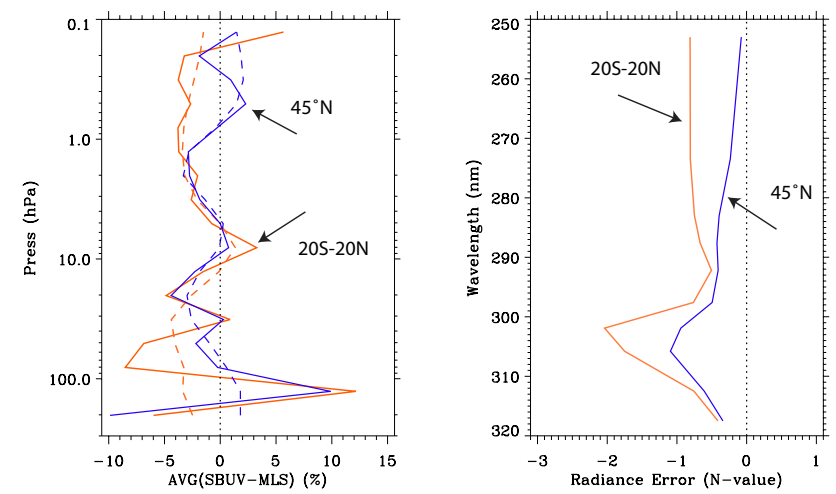

Fig. 15. Left panel shows the bias between NOAA-17/SBUV and Aura/MLS derived by averaging 6 yr of data (2005-2010). The solid lines show unsmoothed data, the dashed lines smoothed data. The smoothed differences are less than $5 \%$ at all altitudes. Variations in unsmoothed data near $100 \mathrm{hPa}$ are caused by systematic differences between MLS and ozonesonde data that were used to construct SBUV a priori. The bias at higher altitudes could be caused by diurnal effects. The right panel shows the implied error in SBUV radiances assuming MLS data have no errors. The magnitude and latitude dependence of errors at the longer wavelengths are larger than the uncertainty in SBUV measurements, implying that the some of SBUV/MLS bias at lower altitudes may be MLS error.

2013). Most importantly, MLS profiles are provided in pressure vs. MR coordinate, which can be converted to SBUV layer ozone without using temperature profiles. The best ozone profile datasets available prior to MLS came from occultation instruments, such as SAGE, that retrieve ozone density as a function of altitude. Though they have been converted into pressure vs. MR scale, the conversion depends upon a NOAA stratospheric temperature record that is not of very high quality, particularly in the upper stratosphere (e.g., Gaffen et al., 2000). Just $100 \mathrm{~m}$ error in geopotential height, derived from NOAA temperature data, produces $\sim 2 \%$ error in converting density profiles into mixing ratio profiles in the upper stratosphere. Finally, since MLS provides data in daytime around 13:30 LT, while NOAA-17 SBUV/2 measured around 09:30 LT, the diurnal variation is less of a problem in comparing SBUV with MLS than it is for occultation instruments.

Figure 15 shows the comparison between the left and right side of Eq. (5), where the left side is the measured anomaly, defined with respect to the SBUV a priori, and the right side is the smoothed MLS anomaly, also defined with respect to the SBUV a priori. This comparison method is similar to that recommended by Rodgers and Connors (2003) to remove the effect of a priori from the comparison, except they move the a priori to the right side and call the expression on the right side "smoothed" high-resolution (HR) profile. We find this terminology confusing since the resultant profile is actually a hybrid of low-pass filtered HR profile and high-pass filtered a priori profile. Still, in either case, the resulting differences 

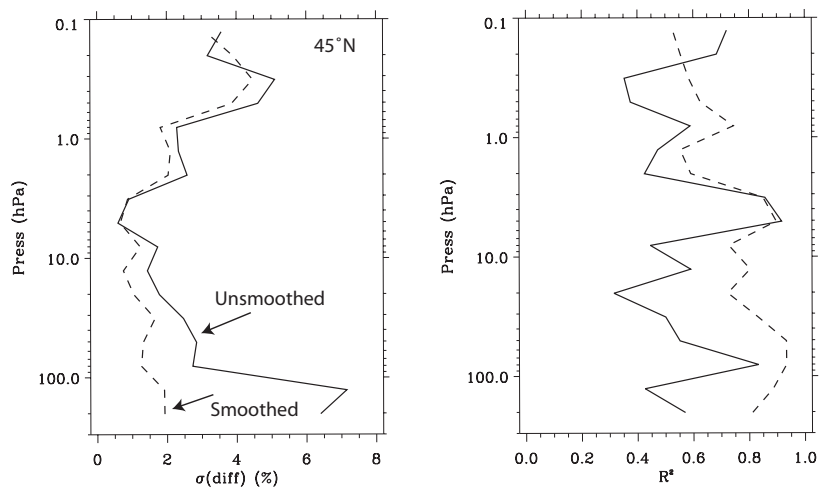

Fig. 16. Standard deviation of difference and anomaly correlation, plotted as $R^{2}$, between NOAA-17/SBUV and Aura/MLS derived using $6 \mathrm{yr}$ of MZMs at $45^{\circ} \mathrm{N}$ (2005-2010). The solid lines show unsmoothed data, the dashed lines smoothed data. Smoothing has large effect in layers where the DFS is small, except in the mesosphere, where the diurnal effects appear to be more important.
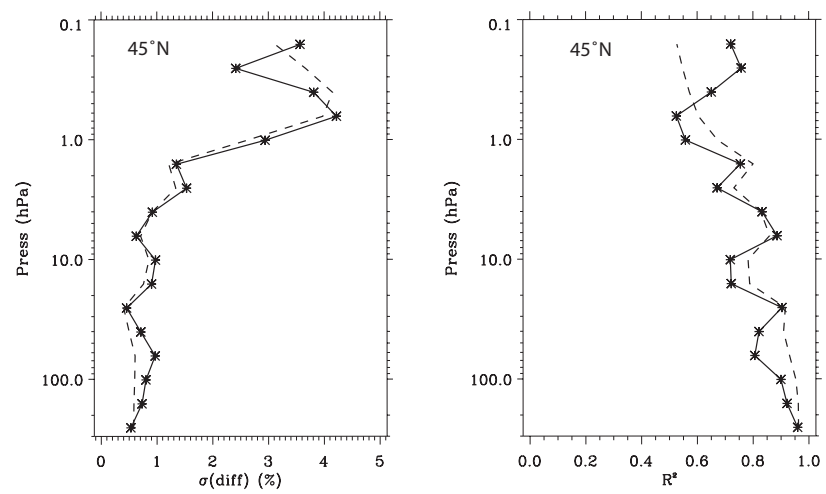

Fig. 17. Same data as used in Fig. 11, except that $\sigma$ and $R^{2}$ are computed for partial column $\mathrm{O}_{3}$ above pressure levels marked by * Smoothing has little effect, implying that SBUV can provide robust estimates of the partial column $\mathrm{O}_{3}$ for constraining models, for providing $\mathrm{O}_{3}$ over-burden above ozonesonde burst altitude, and for cross-calibrating satellite data. Increase in $\sigma$ in the mesosphere may be due to diurnal effects.

are due to combined errors in SBUV and MLS measurements and forward model, e.g., $\mathrm{O}_{3}$ absorption cross-section. Since the accuracy of MLS profiles is $\sim 5 \%$ (Livesey et al., 2013), errors in SBUV appear to be no larger than $5 \%$. Converting these biases into an estimated SBUV $N$ value error reveals latitude- and wavelength-dependent errors that we think are unlikely to be in SBUV measurements. Part of the bias in mesospheric $\mathrm{O}_{3}$ could be due to the $4 \mathrm{~h}$ difference in the local time of the two measurements.

Figures 16-19 show the standard deviation of differences and anomaly correlations between SBUV and MLS in midand low latitudes. In Figs. 16 and 18 we show such statistics for ozone column in $\sim 3.2 \mathrm{~km}$-thick SBUV layers; Figs. 17 and 19 show the statistics for partial ozone columns between the top of the atmosphere and the pressure of a given SBUV
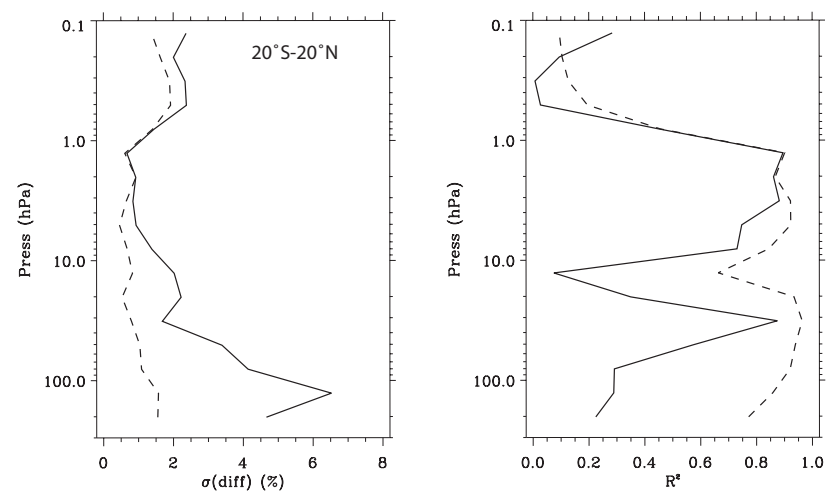

Fig. 18. Same as in Fig. 11 but for tropics $\left(20^{\circ} \mathrm{S}-20^{\circ} \mathrm{N}\right)$. Smoothing has larger effect than at $45^{\circ} \mathrm{N}$ since the layer DFS is smaller in the tropics. Poor correlation in the mesosphere, even with smoothing, is probably due to diurnal effects. Poor correlation at $16 \mathrm{hPa}$ is caused by distortion of the phase of the QBO by SBUV due to vertical smoothing.
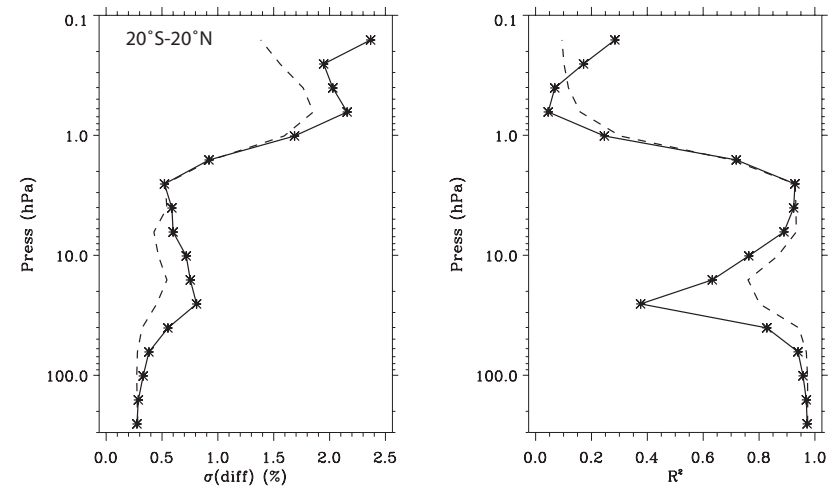

Fig. 19. Same as in Fig. 12 but for tropics $\left(20^{\circ} \mathrm{S}-20^{\circ} \mathrm{N}\right)$. Smoothing has small effect except near $20 \mathrm{hPa}$, where errors caused by the distortion of QBO phase are still significant.

layer. The latter two figures highlight the fact that, although the layer ozone values become less reliable in the lower atmosphere, the partial columns are of much better quality, even without smoothing. For example, the standard deviation of the difference between SBUV and MLS stratospheric columns is less than $1 \%$ and the correlation coefficient squared $\left(R^{2}\right)$ is greater than 0.95 .

Although most results shown in these figures are expected based on the DFS analysis presented in Sect. 3.3, poor performance of SBUV at $\sim 20 \mathrm{hPa}$ in the tropics when compared with unsmoothed MLS data was a surprise. Kramarova et al. (2013a) show that this is caused by the fact that SBUV vertical smoothing distorts the phase of the QBO as it descends in altitude, which then appears as noise when compared with unsmoothed MLS data. Applying SBUV smoothing kernels to MLS removes this effect. Since this problem was previously not well understood, it provides a good example of the value of the smoothing kernels that we now provide in our monthly zonal mean files. 


\section{Summary and conclusions}

We have described the algorithm that has been used to reprocess data from 8 instruments in the SBUV instrument series launched since April 1970. The algorithm has been optimized for estimating MZM profiles by constructing appropriate error covariance matrices. However, the difference between the present algorithm and the one optimized for shortterm variability is likely to be subtle and will show up mostly in the lower atmosphere where the algorithm is more dependent on a priori assumptions.

We have provided a detailed analysis of the information content in SBUV-derived profiles. This analysis shows that the vertical resolution of SBUV-retrieved profiles varies from $\sim 6 \mathrm{~km}$ near $3 \mathrm{hPa}$ to $>15 \mathrm{~km}$ in the lower stratosphere. Though the measurements at longer SBUV wavelengths have high sensitivity to tropospheric $\mathrm{O}_{3}$ variability, the algorithm does not have the necessary vertical resolution to separate the stratosphere from the troposphere. As a result the tropospheric variability gets distributed over a wide range of altitudes. However, this still allows the algorithm to provide very high quality total and stratospheric column $\mathrm{O}_{3}$ information.

Based on comparisons of NOAA-17 SBUV/2 with Aura MLS we find that except at higher altitudes (above $45 \mathrm{~km}$ ) the SBUV- and MLS-derived $\mathrm{O}_{3}$ anomalies correlate very well after MLS anomalies are smoothed using SBUV smoothing kernels. Even without smoothing the correlations are generally quite good outside the tropics. Since $\mathrm{MZM} \mathrm{O}_{3}$ anomalies tend to be quite small (typically $<5 \%$ ), this comparison provides a stringent test of the quality of SBUV measurements for climate and ozone trend studies. Comparisons get worse in the tropics at altitudes where the QBO signal is dominant. This is because the SBUV vertical resolution distorts the complex vertical structure of the QBO signal. Comparisons above $45 \mathrm{~km}$ get worse, probably due to diurnal effects caused by the $4 \mathrm{~h}$ local time difference between the two measurements.

Though the SBUV algorithm does not use the longer wavelengths traditionally used by total $\mathrm{O}_{3}$ measuring instruments, such as TOMS, the quality of MZM total column $\mathrm{O}_{3}$ derived by integrating SBUV profiles appears to be quite good (Labow et al., 2013). Since SBUV uses more ozone sensitive wavelengths than TOMS, it is expected that SBUV total ozone will be less sensitive to instrument drift than TOMS, and since SBUV derives ozone profiles, while TOMS uses a climatological database of ozone profiles, it is expected that SBUV total ozone will be less affected by profile variation at SZA $>80^{\circ}$. However, the latter results are difficult to prove since the best ground-based measurements using direct Sun are not taken at such large angles. Also, since the TOMS calibration was adjusted to SBUV previously, and we are planning to do so in the future when TOMS data are reprocessed, the two datasets should not be considered independent but complementary. While the SBUV data are useful for interannual variability and trend studies, daily maps of total column $\mathrm{O}_{3}$ produced by TOMS are useful for dynamical and process studies, and for evaluating the relative performance of ground-based total ozone measuring instruments. We have also shown that SBUV partial $\mathrm{O}_{3}$ columns, particularly the stratospheric columns, are also of high quality. So, we recommend using such columns for constraining climate-chemistry models, for calculating radiative forcing, and for cross-calibrating various $\mathrm{O}_{3}$ measuring instruments. Though these columns are less affected by SBUV smoothing kernels, for accurate work we still recommend using these kernels to ensure that the results are not significantly affected by smoothing.

Although we have applied a consistent algorithm to process data from all 8 SBUV instruments, the quality of retrieved profiles from these instruments is not necessarily the same. Some instruments in the SBUV series had problems that degraded their data quality and some were partially affected by two volcanic eruptions that injected aerosols in the mid-stratosphere. In addition, SBUV/2 instruments on NOAA satellites have acquired data at different local times. These data are likely to be affected by local time variations in $\mathrm{O}_{3}$ at altitudes above $\sim 10 \mathrm{hPa}$.

\section{Supplementary material related to this article is available online at http://www.atmos-meas-tech.net/6/ 2533/2013/amt-6-2533-2013-supplement.pdf.}

Acknowledgements. We thank Richard Stolarski and Xiong Liu for providing valuable inputs in improving this paper, and LiangKang Huang for his contributions in maintaining SBUV processing software and long-term calibration.

Edited by: C. von Savigny

\section{References}

Ahmad, Z. and Bhartia, P. K.: Effect of molecular anisotropy on backscattered ultraviolet radiance, Appl. Optics, 34, 8309-8314, 1995.

Ahmad, Z., Bhartia, P. K., and Krotkov, N.: Spectral properties of backscattered UV radiation in cloudy atmospheres, J. Geophys. Res.-Atmos., 109, D01201, doi:10.1029/2003jd003395, 2004.

Bass, A. M. and Paur, R. J.: The ultraviolet cross-sections of ozone, I. Measurements, in: Proc. Quad. Ozone Symp., Quad. Ozone Symp., Halkadikki, Greece, 3-7 September 1984, 606616, 1985.

Bhartia, P. K., Herman, J., Mcpeters, R. D., and Torres, O.: Effect of Mount-Pinatubo Aerosols on Total Ozone Measurements from Backscatter Ultraviolet (Buv) Experiments, J. Geophys. Res.Atmos., 98, 18547-18554, 1993.

Bhartia, P. K., McPeters, R. D., Mateer, C. L., Flynn, L. E., and Wellemeyer, C.: Algorithm for the estimation of vertical ozone profiles from the backscattered ultraviolet technique, J. Geophys. Res.-Atmos., 101, 18793-18806, 1996. 
Dave, J. V.: Meaning of Successive Iteration of Auxiliary Equation in Theory of Radiative Transfer, Astrophys. J., 140, 1292-1303, 1964.

Dave, J. V.: Investigation of the effect of atmospheric dust on the determination of total ozone from the earth's ultraviolet reflectivity measurements, Int. Bus. Mach. Corp., Gaithersburg, MD, 1977.

Dave, J. V.: Effect of Aerosols on Estimation of Total Ozone in an Atmospheric Column from Measurements of Its Ultraviolet Radiance, J. Atmos. Sci., 35, 809-911, 1978.

DeLand, M. T., Shettle, E. P., Thomas, G. E., and Olivero, J. J.: Solar backscattered ultraviolet (SBUV) observations of polar mesospheric clouds (PMCs) over two solar cycles, J. Geophys. Res.Atmos., 108, 8445, doi:10.1029/2002JD002398, 2003.

DeLand, M. T., Taylor, S. L., Huang, L. K., and Fisher, B. L.: Calibration of the SBUV version 8.6 ozone data product, Atmos. Meas. Tech., 5, 2951-2967, doi:10.5194/amt-5-2951-2012, 2012.

Flynn, L.: Solar Backscatter Ultraviolet instrument (SBUV/2) version 8 retrieval algorithm theoretical basis document (V8 ATBD), available at: http://acd-ext.gsfc.nasa.gov/ People/Haffner/OCP_clim/v2/OCP_clim_v2.pdf (last access: 29 September 2013), 2007.

Frederick, J. E., Cebula, R. P., and Heath, D. F.: Instrument Characterization for the Detection of Long-term Changes in Stratospheric Ozone: An Analysis of the SBUV/2 Radiometer, J. Atmos. Ocean. Tech., 3, 472-480, 1986.

Froidevaux, L., Jiang, Y. B., Lambert, A., Livesey, N. J., Read, W. G., Waters, J. W., Browell, E. V., Hair, J. W., Avery, M. A., Mcgee, T. J., Twigg, L. W., Sumnicht, G. K., Jucks, K. W., Margitan, J. J., Sen, B., Stachnik, R. A., Toon, G. C., Bernath, P. F., Boone, C. D., Walker, K. A., Filipiak, M. J., Harwood, R. S., Fuller, R. A., Manney, G. L., Schwartz, M. J., Daffer, W. H., Drouin, B. J., Cofield, R. E., Cuddy, D. T., Jarnot, R. F., Knosp, B. W., Perun, V. S., Snyder, W. V., Stek, P. C., Thurstans, R. P., and Wagner, P. A.: Validation of Aura Microwave Limb Sounder stratospheric ozone measurements, J. Geophys. Res.Atmos., 113, D15s20, doi:10.1029/2007jd008771, 2008.

Gaffen, D. J., Sargent, M. A., Habermann, R. E., and Lanzante, J. R.: Sensitivity od tropospheric and stratospheric temperature trends to radiosonde data quality, J. Climate, 13, 1776-1796, 2000.

Haefele, A., Hocke, K., Kampfer, N., Keckhut, P., Marchand, M., Bekki, S., Morel, B., Egorova, T., and Rozanov, E.: Diurnal changes in middle atmospheric $\mathrm{H}(2) \mathrm{O}$ and $\mathrm{O}(3)$ : Observations in the Alpine region and climate models, J. Geophys. Res.-Atmos., 113, D17303, doi:10.1029/2008jd009892, 2008.

Haffner, D.: OMCLDRR Cloud pressure Climatology Summary, available at: http://acd-ext.gsfc.nasa.gov/People/Haffner/OCP clim/v2/OCP_clim_v2.pdf (last access: 29 September 2013), 2011.

Hasekamp, O. P. and Landgraf, J.: Ozone profile retrieval from backscattered ultraviolet radiances: The inverse problem solved by regularization, J. Geophys. Res.-Atmos., 106, 8077-8088, 2001.

Heath, D. F., Krueger, A. J., Roeder, H. A., and Henderson, B. D.: Solar Backscatter Ultraviolet and Total Ozone Mapping Spectrometer (SBUV-TOMS) for Nimbus G, Opt. Eng., 14, 323-331, 1975.
Hilsenrath, E., Williams, D. E., Caffrey, R. T., Cebula, R. P., and Hynes, S. J.: Calibration and Radiometric Stability of the Shuttle Solar Backscatter Ultraviolet (SSBUV) Experiment, Metrologia, 30, 243-248, 1993.

Hoogen, R., Rozanov, V. V., and Burrows, J. P.: Ozone profiles from GOME satellite data: Algorithm description and first validation, J. Geophys. Res.-Atmos., 104, 8263-8280, 1999.

Huang, F. T., Mayr, H. G., Russell, J. M., and Mlynczak, M. G.: Ozone diurnal variations in the stratosphere and lower mesosphere, based on measurements from SABER on TIMED, J. Geophys. Res.-Atmos., 115, D24308, doi:10.1029/2010jd014484, 2010.

Huang, L. K., Cebula, R. P., Taylor, S. L., Deland, M. T., McPeters, R. D., and Stolarski, R. S.: Determination of NOAA$11 \mathrm{SBUV} / 2$ radiance sensitivity drift based on measurements of polar ice cap radiance, Int. J. Remote Sens., 24, 305-314, doi:10.1080/01431160304978, 2003.

Joiner, J., Bhartia, P. K., Cebula, R. P., Hilsenrath, E., McPeters, R. D., and Park, H.: Rotational Raman-Scattering (Ring Effect) in Satellite Backscatter Ultraviolet Measurements, Appl. Optics, 34, 4513-4525, 1995.

Klenk, K. F., Bhartia, P. K., Fleig, A. J., Kaveeshwar, V. G., McPeters, R. D., and Smith, P. M.: Total Ozone Determination from the Backscattered Ultraviolet (BUV) Experiment, J. Appl. Meteorol., 21, 1672-1684, 1982.

Kramarova, N. A., Bhartia, P. K., Frith, S. M., McPeters, R. D., and Stolarski, R. S.: Interpreting SBUV smoothing errors: an example using the quasi-biennial oscillation, Atmos. Meas. Tech., 6, 2089-2099, doi:10.5194/amt-6-2089-2013, 2013a.

Kramarova, N. A., Frith, S. M., Bhartia, P. K., McPeters, R. D., Taylor, S. L., Fisher, B. L., Labow, G. J., and DeLand, M. T.: Validation of ozone monthly zonal mean profiles obtained from the version 8.6 Solar Backscatter Ultraviolet algorithm, Atmos. Chem. Phys., 13, 6887-6905, doi:10.5194/acp-13-6887-2013, 2013 b.

Labow, G. J., McPeters, R. D., Bhartia, P. K., and Kramarova, N.: A comparison of 40 years of SBUV measurements of column ozone with data from the Dobson/Brewer network, J. Geophys. Res. Atmos., 118, 7370-7378, doi:10.1002/jgrd.50503, 2013.

Liu, X., Chance, K., Sioris, C. E., Spurr, R. J. D., Kurosu, T. P., Martin, R. V., and Newchurch, M. J.: Ozone profile and tropospheric ozone retrievals from the Global Ozone Monitoring Experiment: Algorithm description and validation, J. Geophys. Res.-Atmos., 110, D20307, doi:10.1029/2005JD006240, 2005.

Liu, X., Chance, K., Sioris, C. E., and Kurosu, T. P.: Impact of using different ozone cross sections on ozone profile retrievals from Global Ozone Monitoring Experiment (GOME) ultraviolet measurements, Atmos. Chem. Phys., 7, 3571-3578, doi:10.5194/acp7-3571-2007, 2007.

Liu, X., Bhartia, P. K., Chance, K., Spurr, R. J. D., and Kurosu, T. P.: Ozone profile retrievals from the Ozone Monitoring Instrument, Atmos. Chem. Phys., 10, 2521-2537, doi:10.5194/acp-10-25212010, 2010.

Livesey, N., Read, W., Froidevaux, L., Lambert, A., Manney, G., Pumphrey, H., Santee, M., Schwartz, M., Wang, S., Cofield, R., Cuddy, D., Fuller, R., Jarnot, R., Jiang, J., Knosp, B., Stek, P., Wagner, P., and Wu, D.: EOS Aura MLS version 3.3 and 3.4 level 2 data quality and decription document, available at: http://mls.jpl.nasa.gov/data/v3_data_quality_document.pdf (last access: 29 September 2013), 2013. 
Malicet, J., Daumont, D., Charbonnier, J., Parisse, C., Chakir, A., and Brion, J.: Ozone Uv Spectroscopy. 2. Absorption CrossSections and Temperature-Dependence, J. Atmos. Chem., 21, 263-273, 1995.

Mateer, C. L., Heath, D. F., and Krueger, A. J.: Estimation of Total Ozone from Satellite Measurements of Backscattered Ultraviolet Earth Radiance, J. Atmos. Sci., 28, 1307-1311, 1971.

McPeters, R. D.: The Behavior of Ozone near the Stratopause from 2 Years of Buv Observations, J. Geophys. Res.-Oc. Atm., 85, 4545-4550, 1980.

McPeters, R. D.: Climatology of Nitric Oxide in the UpperStratosphere, Mesosphere, and Thermosphere - 1979 through 1986, J. Geophys. Res.-Atmos., 94, 3461-3472, 1989.

McPeters, R. D.: The Atmospheric $\mathrm{SO}_{2}$ Budget for Pinatubo Derived from NOAA-11 SBUV/2 Spectral Data, Geophys. Res. Lett., 20, 1971-1974, 1993.

McPeters, R. D. and Labow, G. J.: Climatology 2011: An MLS and sonde derived ozone climatology for satellite retrieval algorithms, J. Geophys. Res.-Atmos., 117, D10303, doi:10.1029/2011jd017006, 2012.

McPeters, R. D., Labow, G. J., and Logan, J. A.: Ozone climatological profiles for satellite retrieval algorithms, J. Geophys. Res.Atmos., 112, D05308, doi:10.1029/2005JD006823, 2007.

McPeters, R. D., Bhartia, P. K., Haffner, D., Labow, G., and Flynn, L.: The version 8.6 SBUV ozone data record: an overview, J. Geophys. Res., 118, 8032-8039, doi:10.1002/jgrd.50597, 2013.

Meijer, Y. J., Swart, D. P. J., Baier, F., Bhartia, P. K., Bodeker, G. E., Casadio, S., Chance, K., Del Frate, F., Erbertseder, T., Felder, M. D., Flynn, L. E., Godin-Beekmann, S., Hansen, G., Hasekamp, O. P., Kaifel, A., Kelder, H. M., Kerridge, B. J., Lambert, J. C., Landgraf, J., Latter, B., Liu, X., McDermid, I. S., Pachepsky, Y., Rozanov, V., Siddans, R., Tellmann, S., van der A, R. J., van Oss, R. F., Weber, M., and Zehner, C.: Evaluation of Global Ozone Monitoring Experiment (GOME) ozone profiles from nine different algorithms, J. Geophys. Res.-Atmos., 111, D21306, doi:10.1029/2005jd006778, 2006.

Munro, R., Siddans, R., Reburn, W. J., and Kerridge, B. J.: Direct measurement of tropospheric ozone distributions from space, Nature, 392, 168-171, 1998.

Prather, M. J.: Ozone in the Upper-Stratosphere and Mesosphere, J. Geophys. Res.-Oc. Atm., 86, 5325-5338, 1981.

Rodgers, C. D.: Retrieval of Atmospheric-Temperature and Composition from Remote Measurements of Thermal-Radiation, Rev. Geophys., 14, 609-624, 1976.

Rodgers, C. D.: Characterization and Error Analysis of Profiles Retrieved from Remote Sounding Measurements, J. Geophys. Res.Atmos., 95, 5587-5595, 1990.

Rodgers, C. D.: Inverse methods for atmospheric sounding : theory and practice, Series on atmospheric, oceanic and planetary physics, 2, World Scientific, Singapore; River Edge, N.J., xvi, 238 pp., 2000.

Rodgers, C. D. and Connor, B. J.: Intercomparison of remote sounding instruments, J. Geophys. Res., 108, 4116, doi:10.1029/2002JD002299, 2003.

Sakazaki, T., Fujiwara, M., Mitsuda, C., Imai, K., Manago, M., Naito, Y., Nakamura, T., Akiyoshi, H., Kinnison, D., Sano, T., Suzuki, M., and Shiotani, M.: Diurnal ozone variations in the stratosphere revealed in observations from the Sperconducting Submillimeter-Wave Limb-Emission Sounder (SMILES) on board the International Space Station (ISS), J. Geophys. Res.Atmos., 118, 2991-3006, doi:10.1002/jgrd.50220, 2013.

Stolarski, R. S. and Frith, S. M.: Search for evidence of trend slowdown in the long-term TOMS/SBUV total ozone data record: the importance of instrument drift uncertainty, Atmos. Chem. Phys., 6, 4057-4065, doi:10.5194/acp-6-4057-2006, 2006.

Thomas, G. E., Mcpeters, R. D., and Jensen, E. J.: SatelliteObservations of Polar Mesospheric Clouds by the Solar Backscattered Ultraviolet Spectral Radiometer - Evidence of a Solar-Cycle Dependence, J. Geophys. Res.-Atmos., 96, 927939, 1991.

Torres, O. and Bhartia, P. K.: Effect of Stratospheric Aerosol on Ozone Profile from Buv Measurements, Geophys. Res. Lett., 22, 235-238, 1995.

Torres, O. and Bhartia, P. K.: Impact of tropospheric aerosol absorption on ozone retrieval from backscattered ultraviolet measurements, J. Geophys. Res.-Atmos., 104, 21569-21577, 1999.

Torres, O., Herman, J. R., Bhartia, P. K., and Ahmad, Z.: Properties of Mount-Pinatubo Aerosols as Derived from Nimbus-7 Total Ozone Mapping Spectrometer Measurements, J. Geophys. Res.-Atmos., 100, 14043-14055, 1995.

Torres, O., Bhartia, P. K., Herman, J. R., Ahmad, Z., and Gleason, J.: Derivation of aerosol properties from satellite measurements of backscattered ultraviolet radiation: Theoretical basis (Vol. 103, p. 17099, 1998), J. Geophys. Res.-Atmos., 103, 23321-23321, 1998.

Twomey, S. A.: On the Numerical-Solution of Fredholm IntegralEquations of the 1st Kind by the Inversion of the Linear-System Produced by Quadrature, J. Assoc. Comput. Mach., 10, 97-101, 1963.

van $\operatorname{der}$ A, R. J., van Oss, R. F., Piters, A. J. M., Fortuin, J. P. F., Meijer, Y. J., and Kelder, H. M.: Ozone profile retrieval from recalibrated Global Ozone Monitoring Experiment data, J. Geophys. Res.-Atmos., 107, ACH 2.1-ACH 2.10, doi:10.1029/2001JD000696, 2002.

Vasilkov, A. P., Joiner, J., Yang, K., and Bhartia, P. K.: Improving total column ozone retrievals by using cloud pressures derived from Raman scattering in the UV, Geophys. Res. Lett., 31, L20109, doi:10.1029/2004g1020603, 2004.

Vasilkov, A., Joiner, J., Spurr, R., Bhartia, P. K., Levelt, P., and Stephens, G.: Evaluation of the OMI cloud pressures derived from rotational Raman scattering by comparisons with other satellite data and radiative transfer simulations, J. Geophys. Res.Atmos., 113, D15S19, doi:10.1029/2007jd008689, 2008.

Waters, J. W., Read, W. G., Froidevaux, L., Jarnot, R. F., Cofield, R. E., Flower, D. A., Lau, G. K. K., Pickett, H. M., Santee, M. L., Wu, D. L., Boyles, M. A., Burke, J. R., Lay, R. R., Loo, M. S., Livesey, N. J., Lungu, T. A., Manney, G. L., Nakamura, L. L., Perun, V. S., Ridenoure, B. P., Shippony, Z., Siegel, P. H., and Thurstans, R. P.: The UARS and EOS microwave limb sounder (MLS) experiments, J. Atmos. Sci., 56, 194-217, 1999.

Wellemeyer, C. G., Taylor, S. L., Seftor, C. J., McPeters, R. D., and Bhartia, P. K.: A correction for total ozone mapping spectrometer profile shape errors at high latitude, J. Geophys. Res.-Atmos., 102, 9029-9038, 1997. 